\title{
Labour Market Rigidities, Trade and Unemployment
}

\section{Citation}

Helpman, Elhanan and Oleg Itskhoki. 2010. "Labour Market Rigidities, Trade and Unemployment." Review of Economic Studies 77 (3) (February 4): 1100-1137. doi:10.1111/ j.1467-937x.2010.00600.x.

\section{Published Version}

10.1111/j.1467-937X.2010.00600.x

\section{Permanent link}

http://nrs.harvard.edu/urn-3:HUL.InstRepos:25586655

\section{Terms of Use}

This article was downloaded from Harvard University's DASH repository, and is made available under the terms and conditions applicable to Open Access Policy Articles, as set forth at http:// nrs.harvard.edu/urn-3:HUL.InstRepos:dash.current.terms-of-use\#OAP

\section{Share Your Story}

The Harvard community has made this article openly available.

Please share how this access benefits you. Submit a story.

Accessibility 


\title{
Labor Market Rigidities, Trade and Unemployment*
}

\author{
Elhanan Helpman \\ Harvard University and CIFAR
}

\author{
Oleg Itskhoki \\ Harvard University
}

April 30, 2009

\begin{abstract}
We study a two-country two-sector model of international trade in which one sector produces homogeneous products and the other produces differentiated products. Both sectors are subjected to search and matching frictions in the labor market and wage bargaining. As a result, some of the workers searching for jobs end up being unemployed. Countries are similar except for frictions in their labor markets, such as efficiency of matching and costs of posting vacancies, which can vary across the sectors. The differentiated-product industry has firm heterogeneity and monopolistic competition. We study the interaction of labor market rigidities and trade impediments in shaping welfare, trade flows, productivity, and unemployment. We show that both countries gain from trade. A country with relatively lower frictions in the differentiated-product industry exports differentiated products on net. A country benefits from lowering frictions in its differentiate sector's labor market, but this harms the country's trade partner. Alternatively, a simultaneous proportional lowering of labor market frictions in the differentiated sectors of both countries benefits both of them. The opening to trade raises a country's rate of unemployment if its relative labor market frictions in the differentiated sector are low, and it reduces the rate of unemployment if its relative labor market frictions in the differentiated sector are high. Cross-country differences in rates of unemployment exhibit rich patterns. In particular, lower labor market frictions do not ensure lower unemployment, and unemployment and welfare can both rise in response to falling labor market frictions and falling trade costs.
\end{abstract}

Keywords: labor market frictions, unemployment, productivity, trade

JEL Classification: F12, F16, J64

This is a preprint of an Article published in the Review of Economic Studies 77: 1100-1137, 2010.

${ }^{*}$ We thank Alberto Alesina, Pol Antràs, Jonathan Eaton, Emmanuel Farhi, Larry Katz, Kala Krishna, David Laibson, Stephen Redding, the editor and referees for comments, Jane Trahan for editorial assistance, and Helpman thanks the National Science Foundation for financial support. 


\section{Introduction}

International trade and international capital flows link national economies. Although such links are considered to be beneficial for the most part, they produce an interdependence that occasionally has harmful effects. In particular, shocks that emanate in one country may negatively impact trade partners. On the trade side, links through terms-of-trade movements have been studied extensively, and it is now well understood that, say, capital accumulation or technological change can worsen a trade partner's terms of trade and reduce its welfare. On the macro side, the transmission of real business cycles has been widely studied, such as the impact of technology shocks in one country on income fluctuations in its trade partners.

Although a large literature addresses the relationship between trade and unemployment, we fall short of understanding how these links depend on labor market rigidities. Indeed, measures of labor market flexibility developed by Botero et al. (2004) differ greatly across countries. ${ }^{1}$ The rigidity of employment index, which is an average of three other indexes - difficulty of hiring, difficulty of firing, and rigidity of hours - shows wide variation in its range between zero and one hundred (where higher values represent larger rigidities). Importantly, countries with very different development levels may have similar labor market rigidities. For example, Chad, Morocco and Spain have indexes of 60, 63 and 63, respectively, which are about twice the average for the OECD countries (which is 33.3) and higher than the average for sub-Saharan Africa. The United States has the lowest index, equal to zero, while Australia has an index of three and New Zealand has an index of seven, all significantly below the OECD average. Yet some of the much poorer countries also have very flexible labor markets, e.g., both Uganda and Togo have an index of seven. ${ }^{2}$

We develop in this paper a two-country model of international trade in order to study the effects of labor market frictions on trade flows, productivity, welfare and unemployment. We are particularly interested in the impact of a country's labor market rigidities on its trade partner, and the differential impact of lower trade impediments on countries with different labor market rigidities. Blanchard and Wolfers (2000) emphasize the need to allow for interactions between shocks and differences in labor market characteristics in order to explain the evolution of unemployment in European economies. They show that these interactions are empirically important. On the other side, Nickell et al. (2002) emphasize changes over time in labor market characteristics as important determinants of the evolution of unemployment in OECD countries. We focus the analysis on search and matching frictions in Sections 2-5, and discuss in Section 6 how the results generalizations to economies with firing costs and unemployment benefits. ${ }^{3}$

\footnotetext{
${ }^{1}$ Their original data has been updated by the World Bank and is now available at http://www.doingbusiness.org/ExploreTopics/EmployingWorkers/. The numbers reported in the text come from this site, downloaded on May 20, 2007. Other measures of labor market characteristics are available for OECD countries; see Nickell (1997) and Blanchard and Wolfers (2000).

${ }^{2}$ There is growing awareness that institutions affect comparative advantage and trade flows. Levchenko (2007), Nunn (2007) and Costinot (2006) provide evidence on the impact of legal institutions, while Cuñat and Melitz (2007) and Chor (2006) provide evidence on the impact of labor market rigidities.

${ }^{3}$ While we use a static specification of labor market frictions, our analysis is consistent with a steady state of a dynamic model as we show in Helpman and Itskhoki (2009).
} 
The literature on trade and unemployment is large and varied. One strand of this literature considers economies with minimum wages, of which Brecher (1974) represents an early contribution. ${ }^{4}$ Another approach, due to Matusz (1986), uses implicit contracts. A third approach, exemplified by Copeland (1989), incorporates efficiency wages into trade models. ${ }^{5}$ Yet another line of research uses fair wages. Agell and Lundborg (1995) and Kreickemeier and Nelson (2006) illustrate this approach. The final approach uses search and matching in labor markets. While two early studies extended the two-sector model of Jones (1965) to economies with this type of labor market friction, ${ }^{6}$ Davidson, Martin and Matusz (1999) provide a particularly valuable analysis of international trade with labor markets that are characterized by Diamond-Mortensen-Pissarides-type search and matching frictions. ${ }^{7}$ In their model differences in labor market frictions, both across sectors and across countries, generate Ricardian-type comparative advantage. ${ }^{8}$

Our two-sector model incorporates Diamond-Mortensen-Pissarides-type frictions into both sectors; one producing homogenous goods, the other producing differentiated products. In both sectors wages are determined by bargaining. There is perfect competition in homogeneous goods and monopolistic competition in differentiated products. In the differentiated-product sector firms are heterogeneous, as in Melitz (2003). These firms exercise market power in the product market on the one hand, and bargain with workers over wages on the other. ${ }^{9}$ Moreover, there are fixed and variable trade costs in the differentiated sector. We focus the analysis on the differentiated sector and think about the homogeneous sector as the rest of the economy. ${ }^{10}$

We develop the model in stages. The next section describes demand, product markets, labor markets, and the determinants of wages and profits. In the following section, Section 3, we discuss the structure of equilibrium, focusing on the case in which both countries are incompletely specialized, and - as in Melitz (2003) - only a fraction of firms export in the differentiated-product industry and some entrants exit this industry. This is followed by an analysis of the impact of labor market frictions on trade, welfare, and productivity in Section 4. We allow the labor market frictions to vary both across countries and sectors. There we also study the differential impact of lower trade impediments on countries with different labor market frictions. Importantly, we show that both countries gain from trade in welfare terms and in terms of total factor productivity, independently of trade costs and differences in labor market rigidities. The lowering of labor market

\footnotetext{
${ }^{4}$ His approach has been extended by Davis (1998) to study how wages are determined when two countries trade with each other, one with and one without a minimum wage.

${ }^{5}$ See also Brecher (1992) and Hoon (2001).

${ }^{6}$ See Davidson, Martin and Matusz (1988) and Hosios (1990).

${ }^{7}$ See Pissarides (2000) for the theory of search and matching in labor markets.

${ }^{8}$ More work has followed this line of inquiry than the other approaches mentioned in the text. Recent examples include Davidson and Matusz (2006a,b) and Moore and Ranjan (2005).

${ }^{9}$ A surge of papers has incorporated labor market frictions into models with heterogeneous firms. Egger and Kreickemeier (2009) examine trade liberalization in an environment with fair wages and Davis and Harrigan (2007) examine trade liberalization in an environment with efficiency wages; both papers focus on the wage dispersion of identical workers across heterogeneous firms in symmetric countries. Mitra and Ranjan (2007) examine offshoring in an environment with search and matching and Felbermayr, Prat and Schmerer (2008) study trade in a one-sector model with search and matching and symmetric countries.

${ }^{10}$ It is easy to generalize this analysis to multiple differentiated sectors.
} 
frictions in the differentiated sector of one country raises its welfare, but harms the trade partner. Nevertheless, both countries benefit from simultaneous proportional reductions of labor market frictions in the differentiated sector across the world.

By lower frictions in its differentiated sector's labor market a country gains a competitive advantage in this sector, which is reminiscence of a productivity improvement (but not identical). As a result, it attracts more firms into this sector while the foreign country attracts fewer firms. The entry and exit of firms overwhelms the terms of trade movement, leading to welfare gains in the country with improved labor market frictions and welfare losses in its trade partner.

In Section 4 we also show that labor market flexibility is a source of comparative advantage. The country with relatively lower labor market frictions in the differentiated sector (i.e., lower relative to the homogeneous sector) has a larger fraction of exporting firms and it exports differentiated products on net. Moreover, the share of intra-industry trade is smaller while the volume of trade is larger the larger is the difference in relative sectoral labor market rigidities across countries.

In Section 5 we take up unemployment. We show that the relationship between unemployment and labor market rigidity in the differentiated sector is hump-shaped when the countries are symmetric. A decline in labor market frictions in the differentiated sector decreases the sectoral rate of unemployment and induces more workers to search for jobs in the differentiated-product sector. When the differentiated sector has the lower sectoral rate of unemployment, which happens when labor market frictions are relatively lower in this sector, the reallocation of workers across sectors, i.e., the composition effect, reduces the aggregate rate of unemployment. Under these circumstances the aggregate rate of unemployment declines, because both the shift in the sectoral rate of unemployment and the reallocation of workers across sectors reduce the aggregate rate of unemployment. On the other hand, when labor market frictions are higher in the differentiated sector, these two effects impact unemployment in opposite directions, with the composition effect dominating in a highly rigid labor market and the sectoral unemployment effect dominating in a mildly rigid labor market. As a result, unemployment initially increases and then decreases as labor market frictions decline, starting from high levels of rigidity.

We also discuss the transmission of shocks across asymmetric countries, using numerical examples to illustrate various patterns. In particular, we show that in the absence of unemployment in the homogenous sector, if a single country reduces its labor market frictions in the differentiated sector this reduces unemployment in the country's trading partner by inducing a labor reallocation from the differentiated-product sector to the homogeneous-product sector. We also show that lowering trade impediments can increase unemployment in one or both countries, despite its positive welfare effect, and that the interaction between trade impediments and labor market rigidities produces rich patterns of unemployment. Specifically, differences in rates of unemployment across countries do not necessarily reflect differences in labor market frictions; the more flexible country can have higher or lower unemployment, depending on the height of trade impediments and the levels of labor market frictions.

In Section 6 we discuss the impacts of firing costs and unemployment benefits as additional 
sources of labor market frictions. In particular, we describe conditions under which the previous results remain valid, as well as how they change when these conditions are not satisfied. The last section summarizes some of the main insights from this analysis.

\section{The Model}

We develop in this section the building blocks of our analytical model. They consist of a demand structure, technologies, product and labor market structures, and determinants of wages and profits. After describing these ingredients in some detail, we discuss in the next three sections equilibrium interactions in a two-country world. In order to focus on labor market rigidities, we assume that the two countries are identical except for labor market frictions. This means that the demand structure and the technologies are the same in both countries. They can differ in the size of their labor endowment, but this difference is not consequential for the type of equilibrium we discuss in the main text.

\subsection{Preferences and Demand}

Every country has a representative agent who consumes a homogeneous product $q_{0}$ and a continuum of brands of a differentiated product whose real consumption index is $Q$. The real consumption index of the differentiated product is a constant elasticity of substitution aggregator:

$$
Q=\left[\int_{\omega \in \Omega} q(\omega)^{\beta} d \omega\right]^{\frac{1}{\beta}}, \quad 0<\beta<1,
$$

where $q(\omega)$ represents the consumption of variety $\omega, \Omega$ represents the set of varieties available for consumption, and $\beta$ is a parameter that controls the elasticity of substitution between brands.

Consumer preferences between the homogeneous product, $q_{0}$, and the real consumption index of the differentiated product, $Q$, are represented by the quasi-linear utility function ${ }^{11}$

$$
\mathbb{U}=q_{0}+\frac{1}{\zeta} Q^{\zeta}, \quad 0<\zeta<\beta
$$

The restriction $\zeta<\beta$ ensures that varieties are better substitutes for each other than for the outside good $q_{0}$. We also assume that the consumer has a large enough income level to always consume positive quantities of the outside good, in which case it is convenient to choose the outside good as numeraire, so that its price equals one, i.e., $p_{0}=1$. Under the circumstances $p(\omega)$, the price of brand $\omega$, and $P$, the price index of the brands, are measured relative to the price of the homogeneous product.

The utility function $\mathbb{U}$ implies that a consumer with spending $E$ who faces the price index $P$ for the differentiated product chooses $Q=P^{-1 /(1-\zeta)}$ and $q_{0}=E-P^{-\zeta /(1-\zeta)} \cdot{ }^{12}$ As a result, the

\footnotetext{
${ }^{11}$ Alternatively, we could use a homothetic utility function in $q_{0}$ and $Q$; see Appendix for a discussion of this case.

${ }^{12}$ The assumption that consumer spending on the outside good is positive is equivalent to assuming $E>P^{-\zeta /(1-\zeta)}$.
} 
demand function for brand $\omega$ can be expressed as

$$
q(\omega)=Q^{-\frac{\beta-\zeta}{1-\beta}} p(\omega)^{-\frac{1}{1-\beta}}
$$

and the indirect utility function as

$$
\mathbb{V}=E+\frac{1-\zeta}{\zeta} P^{-\frac{\zeta}{1-\zeta}}=E+\frac{1-\zeta}{\zeta} Q^{\zeta}
$$

As usual, the indirect utility function is increasing in spending and declining in price. A higher price index $P$ reduces the demand for $Q$, and-holding expenditure $E$ constant-reduces welfare. This decline in welfare results from the fact that consumer surplus, $(1-\zeta) P^{-\zeta /(1-\zeta)} / \zeta=(1-\zeta) Q^{\zeta} / \zeta$, declines as $P$ rises and $Q$ falls. In what follows, we characterize equilibrium values of $Q$, from which we infer welfare levels.

\subsection{Technologies and Market Structure}

All goods are produced with labor, which is the only factor of production. The market for the homogeneous product is competitive, and this good serves as numeraire, so that $p_{0}=1$. When a firm is matched with a worker, they produce one unit of the homogenous good.

The market for brands of the differentiated product is monopolistically competitive. A firm that seeks to supply a brand $\omega$ bears an entry cost $f_{e}$ in terms of the homogeneous good, which covers the technology cost and the cost of setting up shop in the industry. After bearing this cost, the firm learns how productive its technology is, as measured by $\theta$; a $\theta$-firm requires $1 / \theta$ workers per unit output. In other words, if a $\theta$-firm employs $h$ workers it produces $\theta h$ units of output. Before entry the firm expects $\theta$ to be drawn from a known cumulative distribution $G_{\theta}(\theta)$.

After entry the firm has to bear a fixed production cost $f_{d}$ in terms of the homogeneous good; without it no manufacturing is possible. Following Melitz (2003), we assume that the differentiatedproduct sector bears a fixed cost of exporting $f_{x}$ in terms of the homogeneous product. In addition, it bears a variable cost of exporting of the melting-iceberg type: $\tau>1$ units have to be exported for one unit to arrive in the foreign country. ${ }^{13}$

We label the two countries $A$ and $B$. If a country- $j$ firm, $j=A, B$, with productivity $\theta$ hires $h_{j}$ workers and chooses to serve only the domestic market, then (2) implies that its revenue equals

$$
R_{j}=Q_{j}^{-(\beta-\zeta)} \Theta^{1-\beta} h_{j}^{\beta}
$$

where $\Theta \equiv \theta^{\beta /(1-\beta)}$ is a transformed measure of productivity that is more convenient for our analysis. Higher $Q_{j}$ implies tighter competition in the differentiated product market of country- $j$

Since $\zeta>0$, the demand for $Q$ is elastic and total spending $P Q$ rises when $P$ falls.

${ }^{13}$ As is common in models with home market effects, we assume that there are no trade frictions in the homogeneousproduct sector. We show in our working paper Helpman and Itskhoki (2008) that adding trade costs to the homogenous sector does not affect the results when these costs are not too large. In that paper there are no labor market frictions in the homogenous sector, but the same arguments can be adapted to our framework. 
and proportionately reduces revenues for all firms serving this market.

If, instead, this firm chooses also to export, then it has to allocate output $\theta h_{j}$ across the domestic and foreign markets, i.e., $\theta h_{j}=q_{d j}+q_{x j}$, where $q_{d j}$ represents the quantity allocated to the domestic market and $q_{x j}$ represents the quantity allocated to the export market. ${ }^{14}$ With an optimal allocation of output across markets, the resulting total revenue is

$$
R_{j}=\left[Q_{j}^{-\frac{\beta-\zeta}{1-\beta}}+\tau^{-\frac{\beta}{1-\beta}} Q_{(-j)}^{-\frac{\beta-\zeta}{1-\beta}}\right]^{1-\beta} \Theta^{1-\beta} h_{j}^{\beta}
$$

where $(-j)$ is the index of the country other than $j$. In general, the revenue function of country- $j$ firm with productivity $\theta$ can therefore be represented by

$$
R_{j}\left(\Theta, h_{j}\right)=\left[Q_{j}^{-\frac{\beta-\zeta}{1-\beta}}+I_{x j}(\Theta) \tau^{-\frac{\beta}{1-\beta}} Q_{(-j)}^{-\frac{\beta-\zeta}{1-\beta}}\right]^{1-\beta} \Theta^{1-\beta} h_{j}^{\beta},
$$

where $I_{x j}(\Theta)$ is an indicator variable that equals one if the firm exports and zero otherwise.

\subsection{Wages and Profits}

There are search and matching frictions in every sector and firms post vacancies in order to attract workers. The cost of posting vacancies and the matching process generate hiring costs. Moreover, search and matching frictions generate bilateral monopoly power between a worker and his firm, as a result of which they engage in wage bargaining. ${ }^{15}$

We assume that in the homogeneous-product sector every firm employs one worker. This assumption is common in the search and matching literature (see Pissarides, 2000) and in our case leads to no loss of generality. Since firms in this sector are homogenous in terms of productivity and produce a homogenous good, our analysis does not change if we allow firms to hire multiple workers, as long as they remain price takers.

When a firm and a worker match, they bargain over the surplus from the relationship. Since the outside option of each party equals zero at this stage, the surplus - which consists of the revenue

\footnotetext{
${ }^{14}$ From (2) these quantities have to satisfy

$$
q_{d j}=Q_{j}^{-\frac{\beta-\zeta}{1-\beta}} p_{d j}^{-\frac{1}{1-\beta}} \quad \text { and } \quad q_{x j}=\tau Q_{(-j)}^{-\frac{\beta-\zeta}{1-\beta}}\left(\tau p_{x j}\right)^{-\frac{1}{1-\beta}} .
$$
}

In this specification $p_{d j}$ and $p_{x j}$ are producer prices of home and foreign sales, respectively. Note that when exports are priced at $p_{x j}$, consumers in the foreign country pay an effective price of $\tau p_{x j}$ due to the variable export costs. Under the circumstances they demand $Q_{(-j)}^{-(\beta-\zeta) /(1-\beta)}\left(\tau p_{x j}\right)^{-1 /(1-\beta)}$ consumption units. To deliver these consumption units the supplier has to manufacture $q_{x j}$ units, as shown above. Such a producer maximizes total revenue when marginal revenues are equalized across markets. In the case of constant elasticity of demand functions this requires equalization of producer prices, which implies that the optimal allocation of output satisfies

$$
q_{x j} / q_{d j}=\tau^{-\frac{\beta}{1-\beta}}\left(Q_{(-j)} / Q_{j}\right)^{-\frac{\beta-\zeta}{1-\beta}} .
$$

\footnotetext{
${ }^{15}$ In the earlier working paper version (Helpman and Itskhoki, 2008), we focused on the case in which there are no labor market frictions in the homogeneous-product sector. The current framework incorporates it as a special case (see footnote 20).
} 
from sales of one unit of the homogeneous product - equals one. Assuming equal weights in the bargaining game then implies that the worker gets a wage $w_{0}=1 / 2$ and the firm gets a profit $\pi_{0}=1 / 2$, and these payoffs are the same in every country. We discuss additional details of the labor market equilibrium in this sector in the following section.

In the differentiated-product industry firms are heterogeneous in terms of productivity but face the same cost of hiring in the labor market. A $\Theta$-firm from country $j$ that seeks to employ $h_{j}$ workers bears the hiring cost $b_{j} h_{j}$ in terms of the homogeneous good, where $b_{j}$ is exogenous to the firm yet it depends on sectoral labor market conditions, as we discuss below. It follows that a worker cannot be replaced without cost. Under these circumstances, a worker inside the firm is not interchangeable with a worker outside the firm, and workers have bargaining power after being hired. Workers exploit this bargaining power in the wage determination process.

We assume that the $h_{j}$ workers and the firm engage in strategic wage bargaining with equal weights in the manner suggested by Stole and Zwiebel (1996a,b), which is a natural extension of Nash bargaining to the case of multiple workers. The revenue function (4) then implies that the firm gets a fraction $1 /(1+\beta)$ of the revenue and the workers get a fraction $\beta /(1+\beta) .{ }^{16}$ Recall that $\beta$ determines the concavity of the revenue function in the number of workers; a lower $\beta$ makes the revenue more concave and reduces the revenue loss from the departure of a marginal worker. Therefore, lower $\beta$ reduces the equilibrium share of the workers in the division of revenue. This bargaining outcome is derived under the assumption that at the bargaining stage a worker's outside option is unemployment, and the value of unemployment is zero because there are no unemployment benefits and the model is static. In Section 6 we discuss unemployment benefits, and in Helpman and Itskhoki (2009) we show that our bargaining solution carries over to the steady state of a dynamic model.

Anticipating the outcome of this bargaining game, a $\Theta$-firm that wants to stay in the industry chooses an employment level, $h_{j}$, and whether to serve the foreign market, $I_{x j} \in\{0,1\}$, that maximize profits. That is, it solves the following problem:

$$
\pi_{j}(\Theta) \equiv \max _{\substack{I_{x j} \in\{0,1\}, h_{j} \geq 0 .}}\left\{\frac{1}{1+\beta}\left[Q_{j}^{-\frac{\beta-\zeta}{1-\beta}}+I_{x j} \tau^{-\frac{\beta}{1-\beta}} Q_{(-j)}^{-\frac{\beta-\zeta}{1-\beta}}\right]^{1-\beta} \Theta^{1-\beta} h_{j}^{\beta}-b_{j} h_{j}-f_{d}-I_{x j} f_{x}\right\}
$$

The solution to this problem implies that the employment level of a $\Theta$-firm in country $j$ can be

\footnotetext{
${ }^{16}$ In the solution to the Stole and Zwiebel bargaining game the firm and a worker equally divide the marginal surplus from their relationship, i.e.,

$$
\frac{\partial}{\partial h}\left[R_{j}(\Theta, h)-w_{j}(\Theta, h) h\right]=w_{j}(\Theta, h)
$$

where $w_{j}(\Theta, h)$ is the bargained wage rate in a $\Theta$-firm in country- $j$ which employs $h$ workers. Therefore, the left-hand side represents the surplus of the firm from employing the marginal worker, accounting for the fact that his departure will impact the wage rate of the remaining workers. The wage on the right-hand side is the worker's surplus. Using the expression for revenue (4), the above condition represents a differential equation for the wage schedule which yields the solution $w_{j}(\Theta, h)=\beta /(1+\beta) \cdot R_{j}(\Theta, h) / h$.
} 
decomposed into

$$
h_{j}(\Theta)=h_{d j}(\Theta)+I_{x j}(\Theta) h_{x j}(\Theta),
$$

where $h_{d j}(\Theta)$ represents employment for domestic sales, $h_{x j}(\Theta)$ represents employment for export sales, and

$$
\left.\begin{array}{c}
h_{d j}(\Theta)=\phi_{1}^{\frac{1}{\beta}} b_{j}^{-\frac{1}{1-\beta}} Q_{j}^{-\frac{\beta-\zeta}{1-\beta}} \Theta, \\
h_{x j}(\Theta)=\phi_{1}^{\frac{1}{\beta}} b_{j}^{-\frac{1}{1-\beta}} \tau^{-\frac{\beta}{1-\beta}} Q_{(-j)}^{-\frac{\beta-\zeta}{1-\beta}} \Theta,
\end{array}\right\}
$$

where

$$
\phi_{1}=\left(\frac{\beta}{1+\beta}\right)^{\frac{\beta}{1-\beta}} .
$$

Furthermore, a country- $j$ firm with productivity $\Theta$ pays wages

$$
w_{j}(\Theta)=\frac{\beta}{1+\beta} \frac{R_{j}(\Theta)}{h_{j}(\Theta)}=b_{j}
$$

where the first equality is the outcome of the bargaining game and the second equality follows from the optimal employment condition (6). Firms find it optimal to increase their employment up to the point at which the bargaining outcome is a wage rate equal to the cost of replacing a worker, $b_{j}$. Since this hiring cost is common across all firms, in equilibrium country- $j$ firms of all productivity levels, exporters and non-exporters alike, pay equal wages, $w_{j}=b_{j} .{ }^{17}$

Finally, the operating profits of a $\Theta$-firm in country- $j$ are

$$
\pi_{j}(\Theta)=\pi_{d j}(\Theta)+I_{j}(\Theta) \pi_{x j}(\Theta)
$$

where $\pi_{d j}(\Theta)$ represents operating profits from domestic sales, $\pi_{x j}(\Theta)$ represents operating profits from export sales, and

$$
\left.\begin{array}{c}
\pi_{d j}(\Theta)=\phi_{1} \phi_{2} b_{j}^{-\frac{\beta}{1-\beta}} Q_{j}^{-\frac{\beta-\zeta}{1-\beta}} \Theta-f_{d}, \\
\pi_{x j}(\Theta)=\phi_{1} \phi_{2} b_{j}^{-\frac{\beta}{1-\beta}} \tau^{-\frac{\beta}{1-\beta}} Q_{(-j)}^{-\frac{\beta-\zeta}{1-\beta}} \Theta-f_{x},
\end{array}\right\}
$$

where

$$
\phi_{2}=\frac{1-\beta}{1+\beta}
$$

Note that higher labor market rigidity, reflected in a higher $b_{j}$, reduces proportionately gross operating profits (i.e., not accounting for fixed costs) in the domestic and foreign market. Therefore,

\footnotetext{
${ }^{17}$ This equilibrium outcome generalizes to other revenue functions and bargaining concepts as long as firms are allowed to vary their employment and the marginal hiring costs are equal across the firms. Helpman, Itskhoki and Redding (2009) develop a richer model, in which there is unobserved worker heterogeneity in addition to firm heterogeneity, wages are higher in more productive firms, and exporters pay a wage premium. Bernard and Jensen (1995) and Fariñas and Martín-Marcos (2007) provide evidence to the effect that exporting firms pay higher wages.
} 
an increase in $b_{j}$ is similar to a proportional reduction in the productivity of all country $j$ 's firms.

The profit functions in (8) imply that exporting is profitable if and only if $\pi_{x j}(\Theta) \geq 0$, i.e., there exists a cutoff productivity level, $\Theta_{x j}$, defined by

$$
\pi_{x j}\left(\Theta_{x j}\right)=0
$$

such that all firms with productivity above this cutoff export (provided they choose to stay in the industry) and all firms with productivity below it do not export. Firms with low productivity that do not export may nevertheless make money from supplying the domestic market. For this to be the case, their productivity has to be at least as high as $\Theta_{d j}$, implicitly defined by

$$
\pi_{d j}\left(\Theta_{d j}\right)=0 .
$$

We shall consider equilibria in which $\Theta_{x j}>\Theta_{d j}>\Theta_{\min } \equiv \theta_{\min }^{\beta /(1-\beta)}$, where $\theta_{\min }$ is the lowest productivity level in the support of the distribution $G_{\theta}(\theta)$. That is, equilibria in which highproductivity firms profitably export and supply the domestic market, intermediate-productivity firms cannot profitably export but can profitably supply the domestic market, and low-productivity firms cannot make money and exit. Anticipating this outcome, a prospective firm enters the industry only if expected profits from entry are at least as high as the entry cost $f_{e}$. Therefore the free-entry condition is

$$
\int_{\Theta_{d j}}^{\infty} \pi_{d j}(\Theta) d G(\Theta)+\int_{\Theta_{x j}}^{\infty} \pi_{x j}(\Theta) d G(\Theta)=f_{e}
$$

where $G(\Theta)$ is the distribution of $\Theta$ induced by $G_{\theta}(\theta)$. The first integral represents expected profits from domestic sales, while the second integral represents expected profits from foreign sales. In equilibrium expected profits just equal entry costs.

\subsection{Labor Market}

A country is populated by families. Each family has a fixed supply of $L$ workers, and the family is the representative consumer whose preferences were described in Section 2.1. We assume that there is a continuum of identical families in every country, and the measure of these families equals one in every country. ${ }^{18}$

A family in country $j$ allocates workers to sectors $-N_{j}$ workers to the differentiated-product sector and $N_{0 j}=L-N_{j}$ workers to the homogeneous-product sector-which determines in which sector every worker searches for work. Once committed to a sector, a worker cannot switch sectors. Thus, there is perfect intersectoral mobility ex ante and no mobility ex post.

Let the matching function in the homogeneous sector be Cobb-Douglas, so that $H_{0 j}=m_{0 j} V_{0 j}^{\chi} N_{0 j}^{1-\chi}$

\footnotetext{
${ }^{18}$ When preferences are homothetic rather than quasi-linear, the family interpretation is useful but not essential. See Appendix and Helpman, Itskhoki and Redding (2009) for a discussion of homothetic preferences, risk aversion and ex-post inequality.
} 
is the number of matches when the number of vacancies in the sector equals $V_{0 j}$ and the number of workers searching for jobs in the sector equals $N_{0 j}$, where $0<\chi<1$. We allow the efficiency of the matching process, as measured by $m_{0 j}$, to vary across countries. It follows that output of homogenous products equals $H_{0 j}$, the probability of a worker finding a job in this sector equals $x_{0 j} \equiv H_{0 j} / N_{0 j}=m_{0 j}\left(V_{0 j} / N_{0 j}\right)^{\chi}$, and the probability of a firm finding a worker equals $H_{0 j} / V_{0 j}=m_{0 j}\left(N_{0 j} / V_{0 j}\right)^{1-\chi}=m_{0 j}^{1+\alpha} x_{0 j}^{-\alpha}$, where $\alpha \equiv(1-\chi) / \chi>0 .{ }^{19}$ We shall use $x_{0 j}$ as our measure of tightness in the sector's labor market.

Next assume that the cost of posting vacancies equals $v_{0 j}$ per worker in country $j$, measured in terms of the homogenous good. Then a firm's entry cost into the industry equals $v_{0 j}$. After paying this cost the firm is matched with a worker with probability $m_{0 j}^{1+\alpha} x_{0 j}^{-\alpha}$ and not matched otherwise. When the firm is matched with a worker they bargain over the surplus from the relationship, as described in the previous section; the worker gets a wage $w_{0}=1 / 2$ and the firm gets a profit $\pi_{0}=1 / 2$. Under these circumstances expected profits equal $m_{0 j}^{1+\alpha} x_{0 j}^{-\alpha} / 2$ and firms enter up to the point at which these expected profits cover the entry cost $v_{0 j}$. In other words, in equilibrium tightness in the labor market equals ${ }^{20}$

$$
x_{0 j}=a_{0 j}^{-1 / \alpha}, \quad a_{0 j} \equiv \frac{2 v_{0 j}}{m_{0 j}^{1+\alpha}}>1 .
$$

The derived parameter $a_{0 j}$ summarizes labor market frictions in the homogeneous sector; it rises with the cost of vacancies and declines with the efficiency of the matching process. Evidently, tightness in the labor market declines with $a_{0 j}$.

The expected income of a worker searching for a job in the homogenous sector is $\omega_{0 j}=x_{0 j} w_{0 j}$, which together with (12) yields

$$
\omega_{0 j}=\frac{1}{2} a_{0 j}^{-1 / \alpha}
$$

That is, the expected income of this worker rises with the efficacy of matching in the homogeneous sector and declines with the cost of vacancies. Finally, note that as a result of free entry of firms, the cost of hiring per worker, $b_{0 j} \equiv v_{0 j} V_{0 j} / H_{0 j}=\left(v_{0 j} / m_{0 j}^{1+\alpha}\right) x_{0 j}^{\alpha}$, equals one half in the homogeneous sector in both countries:

$$
b_{0 j}=\frac{1}{2} a_{0 j} x_{0 j}^{\alpha}=\frac{1}{2} .
$$

We now turn to the differentiated sector. Let $H_{j}$ be aggregate employment in the differentiated sector. An individual searching for work in the differentiated-product sector expects to find a job with probability $x_{j}=H_{j} / N_{j}$, where $x_{j}$ measures the degree of tightness in the sector's labor

\footnotetext{
${ }^{19}$ Below we impose parameter restrictions which ensure that matching probabilities are between zero and one. In a dynamic model with continuous time these probabilities are replaced by hazard rates which can take arbitrary positive values including the limiting case of frictionless labor market. We show in Helpman and Itskhoki (2009) that this type of dynamic specification yields steady state outcomes which are similar to our static specification.

${ }^{20}$ We assume that $m_{0 j}^{1+\alpha}<2 v_{0 j}<1$, which ensures that the probability of a worker finding a job and the probability of a firm finding a worker are both smaller than one. Alternatively, when $m_{0 j}^{1+\alpha}=2 v_{0 j}=1$, workers and firms are matched with probability one and there is full employment in the homogenous sector, as in Helpman and Itskhoki (2008).
} 
market. Conditional on finding a job an individual expects to be paid a wage $w_{j}=b_{j}$ (see (7)). Therefore the expected income from searching for a job in the differentiated sector is $x_{j} b_{j}$.

A family allocates workers to sectors so as to maximize the family's aggregate income. A worker allocated to the homogeneous sector earns an expected income of $\omega_{0 j}$, given in (13). On the other hand, a worker allocated to the differentiated sector earns an expected income of $x_{j} b_{j}$. In an equilibrium with employment in both sectors the two expected incomes have to be equal. That is, a family chooses $0<N_{j}<L_{j}$ only if ${ }^{21}$

$$
x_{j} b_{j}=\omega_{0 j}
$$

Unemployment in the differentiated sector is an equilibrium outcome when $x_{j}<1$. We provide below parameter restrictions that ensure this condition.

We now interpret the parameter $b_{j}$ of the cost-of-hiring function $b_{j} h$; this variable is exogenous to the firm but endogenous to the industry. As in the homogeneous sector, workers in the differentiated sector are randomly matched with firms. The number of successful matches is $H_{j}=m_{j} V_{j}^{\chi} N_{j}^{1-\chi}$ in country $j$, where $V_{j}$ is the number of vacancies and $N_{j}$ is the number of individuals searching for jobs in this sector. Note that $\chi$ is the same here as in the matching function of the homogenous sector, but $m_{j}$ - which measures the efficiency of matching - is allowed to differ across countries and sectors. It follows that when the cost per vacancy is $v_{j}$ in the differentiated sector of country $j$, then the cost of hiring is $b_{j}=v_{j} V_{j} / H_{j}$ per worker, and $b_{j}$ can be related in a simple way to tightness in the labor market $x_{j} .^{22}$

$$
b_{j}=\frac{1}{2} a_{j} x_{j}^{\alpha}, \quad a_{j} \equiv \frac{2 v_{j}}{m_{j}^{1+\alpha}},
$$

where $a_{j}$ is our measure of frictions in the differentiated sector's labor market, which is increasing in the cost of vacancies and decreasing in the productivity of matching. Note the symmetry in the modeling of hiring costs in the homogenous and differentiated sectors (compare (16) with (14)).

Next note that (12)-(16) uniquely determine the hiring cost $b_{j}$ and tightness in the labor market $x_{j}$ :

$$
\left.\begin{array}{c}
x_{j}=x_{0 j}\left(\frac{a_{0 j}}{a_{j}}\right)^{\frac{1}{1+\alpha}}=\left(\frac{1}{a_{0 j}^{1 / \alpha} a_{j}}\right)^{\frac{1}{1+\alpha}}, \\
w_{j}=b_{j}=b_{0 j}\left(\frac{a_{j}}{a_{0 j}}\right)^{\frac{1}{1+\alpha}}=\frac{1}{2}\left(\frac{a_{j}}{a_{0 j}}\right)^{\frac{1}{1+\alpha}} \cdot
\end{array}\right\}
$$

Note that $x_{j}<1$ and there is unemployment in the differentiated sector if and only if $a_{0 j} a_{j}^{\alpha}>1$, which we assume to be satisfied. It follows from this characterization that whenever a country has the same labor market frictions in both sectors, so that $a_{0 j}=a_{j}$, it has the same labor market tightness in both sectors and the same cost of hiring in both sectors. Yet while the cost of hiring is

\footnotetext{
${ }^{21}$ This is similar to the indifference between staying in the countryside and migrating to the city in the Harris and Todaro (1970) model. A similar condition holds in the Amiti and Pissarides (2005) model, which is otherwise quite different from ours.

${ }^{22}$ See Blanchard and Gali (2008) for a similar specification.
} 
independent in this case from the common level of labor market frictions because $b_{0 j}=b_{j}=1 / 2$, tightness in the sectoral labor markets declines with the level of frictions. This implies that when $a_{0 j}=a_{j}$ in both countries no country has comparative advantage in one of the sectors (see the discussion in the next section), even when the level of labor market frictions varies across countries. In Helpman and Itskhoki (2009) we show that similar patterns arise in the steady state of a dynamic model.

In what follows we assume that $a_{A} / a_{0 A}>a_{B} / a_{0 B}$, so that country $B$ has relatively lower labor market frictions in the differentiated sector. This implies $b_{A}>b_{B}$, i.e., country $A$ has a larger hiring cost in the differentiated sector, and $x_{A} / x_{0 A}<x_{B} / x_{0 B}$, i.e., the sectoral labor market tightness is relatively lower in the differentiated sector of country $A$. Note, however, that our assumption on relative sectoral labor market frictions has no implications for whether the labor market is tighter in one sector or the other. When $a_{j} / a_{0 j}>1$ in both countries, sectoral tightness is higher in the homogeneous sector in both countries; when $a_{j} / a_{0 j}<1$ in both countries, sectoral tightness is higher in the differentiated sector in both countries; and when $a_{A} / a_{0 A}>1>a_{B} / a_{0 B}$, sectoral tightness is higher in the homogenous sector in country $A$ and higher in the differentiated sector in country $B$. Sectoral labor market frictions can differ due to the fact that it may be more difficult to match workers with firms in some sectors than in other, and labor market frictions can differ across countries due to differences in matching efficiency or differences in costs of posting vacancies. ${ }^{23}$ We allow these possibilities in order to accommodate variation in sectoral rates of unemployment, which feature in the data. ${ }^{24}$

Evidently, the model is bloc recursive, in the sense that the equilibrium wage rate and tightness in the labor market are uniquely determined by labor market frictions. We show in Section 6 that this property also holds with firing costs and unemployment benefits. The implication is that labor market frictions determine $\left(b_{j}, x_{j}\right)$ in country $j$, and these in turn impact other endogenous variables, such as trade, welfare and unemployment.

The sectoral rates of unemployment are $1-x_{0 j}$ in the homogenous sector and $1-x_{j}$ in the differentiated sector. As a result, the economy-wide rate of unemployment can be expressed as

$$
u_{j}=\frac{N_{0 j}}{L}\left(1-x_{0 j}\right)+\frac{N_{j}}{L}\left(1-x_{j}\right)
$$

which is a weighted average of the sectoral rates of unemployment, where the weights are the fractions of workers seeking jobs in every sector. It follows that the unemployment rate can rise either because it rises in one or both sectors or because more individuals search for work in the sector with a higher rate of unemployment.

\footnotetext{
${ }^{23}$ In a dynamic model sectors may differ in separation rates, which leads to $b_{0 j} \neq b_{j}$; see Helpman and Itskhoki (2009). Specifically, we show that if the differentiated sector has a higher separation rate it leads to greater turnover in this sector and a country with more efficient matching technology has a comparative advantage in this sector. Furthermore, policy differences can be a source of cross-country variation in labor market frictions, which we discuss in Section 6.

${ }^{24}$ To illustrate, the BLS reports that in 2007 Mining had an unemployment rate of 3.4\%, Construction had $7.4 \%$, and Manufacturing had 4.3\% (see http://www.bls.gov/cps/cpsaat26.pdf, accessed on April 25, 2008).
} 


\section{Equilibrium Structure}

We focus on equilibria with incomplete specialization, in which every country produces homogeneous and differentiated products. Conditions for incomplete specialization are described in the Appendix, and in our earlier working paper (Helpman and Itskhoki, 2008) we discuss properties of equilibria with complete specialization. This section is devoted to a description of equilibria and some of their properties. More substantive results, which build on this section, are developed and discussed in subsequent sections.

Equations (8)-(10) yield the following expressions for the domestic market and export cutoffs:

$$
\left.\begin{array}{c}
\Theta_{d j}=\frac{1}{\phi_{1} \phi_{2}} f_{d} b_{j}^{\frac{\beta}{1-\beta}} Q_{j}^{\frac{\beta-\zeta}{1-\beta}}, \\
\Theta_{x j}=\frac{1}{\phi_{1} \phi_{2}} f_{x} b_{j}^{\frac{\beta}{1-\beta}} \tau^{\frac{\beta}{1-\beta}} Q_{(-j)}^{\frac{\beta-\zeta}{1-\beta}} \cdot
\end{array}\right\}
$$

Now substitute these expressions into (8) and the resulting profit functions into the free-entry condition (11) to obtain

$$
f_{d} \int_{\Theta_{d j}}^{\infty}\left(\frac{\Theta}{\Theta_{d j}}-1\right) d G(\Theta)+f_{x} \int_{\Theta_{x j}}^{\infty}\left(\frac{\Theta}{\Theta_{x j}}-1\right) d G(\Theta)=f_{e}, \quad j=A, B .
$$

This form of the free-entry condition generates a curve in $\left(\Theta_{d j}, \Theta_{x j}\right)$ space on which every country's cutoffs have to be located, because this curve depends only on the common cost variables and on the common distribution of productivity. Moreover, this curve is downward-sloping, as depicted by $F F$ in Figure 1, and each country has to be located above the $45^{\circ}$ line for the export cutoff to be higher than the domestic cutoff. ${ }^{25}$

Also note that as the export cutoff goes to infinity, the domestic cutoff approaches the cutoff of a closed economy, which is represented by $\Theta_{d}^{c}$ in the figure. It therefore follows that if the cutoff $\Theta_{d}$ in the closed economy is larger than $\Theta_{\min }$, so is $\Theta_{d}$ in the open economy. ${ }^{26}$ Finally note that (19) yields

$$
\frac{\Theta_{x j}}{\Theta_{d(-j)}}=\frac{f_{x} \tau^{\frac{\beta}{1-\beta}}}{f_{d}}\left[\frac{b_{j}}{b_{(-j)}}\right]^{\frac{\beta}{1-\beta}}, \quad j=A, B .
$$

Equations (20) and (21) can be used for solving the four cutoffs as functions of labor market frictions

\footnotetext{
${ }^{25}$ Note, from (19), that in a symmetric equilibrium, in which $Q_{j}=Q_{(-j)}$, the export cutoff is higher if and only if $\tau^{\beta /(1-\beta)} f_{x}>f_{d}$, which is the condition required for exporters to be more productive in Melitz (2003). We assume for convenience that this condition is satisfied for all $\tau \geq 1$ which requires $f_{x}>f_{d}$.

${ }^{26}$ The autarky production cutoff is the solution to

$$
f_{d} \int_{\Theta_{d}^{c}}^{\infty}\left(\frac{\Theta}{\Theta_{d}^{c}}-1\right) d G(\Theta)=f_{e}
$$

which does not depend on labor market frictions. Note also that $\Theta_{d}^{c}>\Theta_{\min }$ if and only if $\left(\bar{\Theta} / \Theta_{\min }\right)>1+f_{e} / f_{d}$, where $\bar{\Theta}$ is the mean of $\Theta$, which we assume to be satisfied. This results from the fact that the integral on the left-hand side of the above equation is decreasing in $\Theta_{d}^{c}$ and assumes its largest value of $\left(\bar{\Theta} / \Theta_{\min }\right)-1$ when $\Theta_{d}^{c}=\Theta_{\text {min }}$.
} 


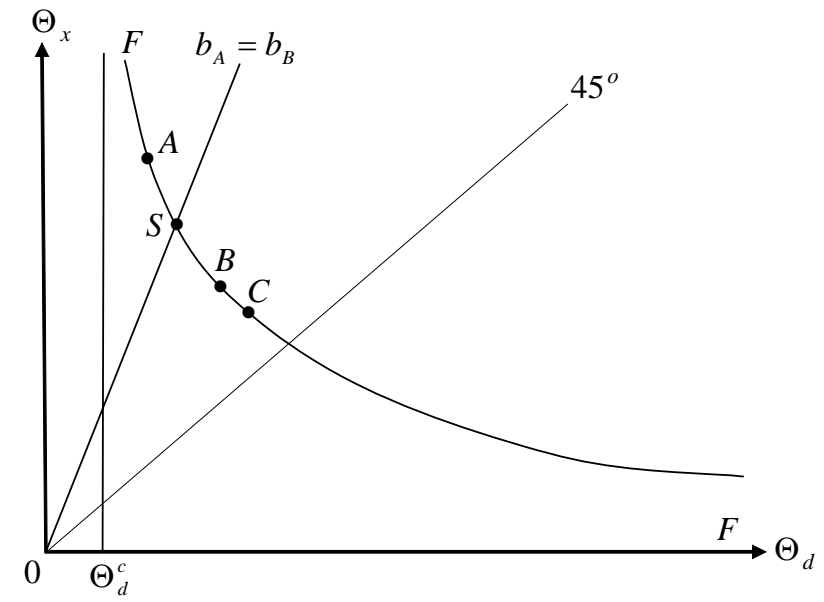

Figure 1: Cutoffs in a trading equilibrium

and cost parameters. As is evident, the cutoffs do not depend on the levels of the hiring costs $b_{j}$, only on their relative size. And once the cutoffs have been solved, they can be substituted into (19) to obtain solutions for the real consumption indexes $Q_{j}$.

Our primary interest is in the influence of trade and labor market frictions on the trading countries. We therefore use (20) and (21) to calculate the impact of these variables on the cutoffs, obtaining

$$
\left.\begin{array}{c}
\hat{\Theta}_{d j}=\frac{\delta_{x j}}{\Delta}\left[-\left(\delta_{x(-j)}+\delta_{d(-j)}\right)\left(\hat{b}_{j}-\hat{b}_{(-j)}\right)-\left(\delta_{d(-j)}-\delta_{x(-j)}\right) \hat{\tau}\right] \\
\hat{\Theta}_{x j}=\frac{\delta_{d j}}{\Delta}\left[\left(\delta_{x(-j)}+\delta_{d(-j)}\right)\left(\hat{b}_{j}-\hat{b}_{(-j)}\right)+\left(\delta_{d(-j)}-\delta_{x(-j)}\right) \hat{\tau}\right]
\end{array}\right\}
$$

where

$$
\delta_{d j}=\frac{f_{d}}{\Theta_{d j}} \int_{\Theta_{d j}}^{\infty} \Theta d G(\Theta), \quad \delta_{x j}=\frac{f_{x}}{\Theta_{x j}} \int_{\Theta_{x j}}^{\infty} \Theta d G(\Theta), \quad \Delta=\frac{1-\beta}{\beta}\left(\delta_{d A} \delta_{d B}-\delta_{x A} \delta_{x B}\right)
$$

Note that $\delta_{d j} / \phi_{2}$ is average revenue per entering firm from domestic sales in country $j$ and $\delta_{x j} / \phi_{2}$ is average revenue per entering firm from export sales. ${ }^{27}$ Moreover, $\delta_{d j}$ equals average gross operating profits (not accounting for fixed costs) per entering firm from domestic sales and $\delta_{x j}$ equals average gross operating profits per entering firm from exporting.

Building on these insights, we prove in the Appendix the following lemmas:

\footnotetext{
${ }^{27}$ To see this, note that profit maximization $(5)$ implies $\pi_{z j}(\Theta)=\phi_{2} R_{z j}(\Theta)-f_{z}$ for $z=d, x$, where $R_{d j}(\Theta)$ is revenue from domestic sales and $R_{x j}(\Theta)$ is revenue from foreign sales. Then, from the zero profit conditions (9)-(10), we have $R_{z j}(\Theta)=f_{z} / \phi_{2} \cdot \Theta / \Theta_{z j}$. As a result, the average revenues per entering firm from domestic sales and exports equal

$$
\int_{\Theta_{z j}}^{\infty} R_{z j}(\Theta) d G(\Theta)=\frac{f_{z}}{\phi_{2} \Theta_{z j}} \int_{\Theta_{z j}}^{\infty} \Theta d G(\Theta)=\frac{\delta_{z j}}{\phi_{2}}, \quad z=d, x .
$$
}


Lemma 1 Let $b_{A}>b_{B}$. Then $\Theta_{d A}<\Theta_{d B}$ and $\Theta_{x A}>\Theta_{x B}$.

Lemma 2 An increase in $\tau$ raises the export cutoff $\Theta_{x j}$ and reduces the domestic cutoff $\Theta_{d j}$ in both countries.

Lemma 3 Let $b_{A}>b_{B}$. Then $Q_{A}<Q_{B}$.

The first lemma shows that in the country with the relatively higher labor market frictions in the differentiated sector exporting requires higher productivity at the firm level and that firms with lower productivity at the bottom of the productivity distribution break even. The former result is quite intuitive; a disadvantage in labor costs needs to be compensated with a productivity advantage to make exporting profitable. The latter stems from the fact that in a country with higher $b_{j}$ expected profits from exporting are lower at the entry stage, which has to be offset by higher expected profits from domestic sales in order for the free entry condition to be satisfied. This implies that lower-productivity firms find it profitable to serve the domestic market. The second lemma just restates a well know result from Melitz (2003) which also holds in our framework: Higher variable trade costs cut into export profits, enabling only more productive firms to profitably export. Under the circumstances lower productivity firms need to survive entry in order to be able to cover the entry cost. The third lemma states that the country with higher relative labor market frictions in the differentiated sector has lower real consumption of differentiated products. This stems from the home market effect. Due to the presence of trade costs, a country suffers a disadvantage in the local supply of differentiated products when its $b_{j}$ is higher in the differentiated industry.

For our equations to describe an equilibrium with incomplete specialization, it is necessary to ensure positive entry of firms in both countries, i.e., $M_{j}>0$ for $j=A, B$, where $M_{j}$ is the number of firms that enter the differentiated sector in country $j$. This places restrictions on the permissible difference across countries in labor market rigidities. To derive the implications of these restrictions, first recall that $Q_{j}^{\zeta}=P_{j} Q_{j}$ is total spending on differentiated products in country $j$, and $M_{j} \delta_{z j} / \phi_{2}$ is total revenue from domestic sales when $z=d$ and from foreign sales when $z=x$. Since aggregate spending has to equal aggregate revenue in market $j$, we have

$$
Q_{j}^{\zeta}=M_{j} \frac{\delta_{d j}}{\phi_{2}}+M_{(-j)} \frac{\delta_{x(-j)}}{\phi_{2}}
$$

where the first term on the right-hand side is revenues of domestic firms and the second term is revenues of foreign firms from sales in country $j$ 's market. Having solved for the cutoffs, which uniquely determine the $\delta_{z j} \mathrm{~s}$, and the real consumption indexes, $Q_{j} \mathrm{~s}$, these equations for $j=A, B$ yield the following solutions for the number of entrants:

$$
M_{j}=\frac{(1-\beta) \phi_{2}}{\beta \Delta}\left[\delta_{d(-j)} Q_{j}^{\zeta}-\delta_{x(-j)} Q_{(-j)}^{\zeta}\right]
$$

We show in the Appendix that they imply: 
Lemma 4 In an equilibrium with incomplete specialization: (i) $\delta_{d j}>\delta_{x j}$ in both countries; (ii) if $b_{A}>b_{B}$, then $\delta_{d A}>\delta_{d B}$ and $\delta_{x A}<\delta_{x B}$.

Lemma 5 Let $b_{A}>b_{B}$. Then $M_{A}<M_{B}$.

Lemma 4 is a technical lemma, which describes conditions that hold in an equilibrium with incomplete specialization. The economic implication of part (i) is that average revenue per entering firm from domestic sales exceeds average revenue per entering firm from export sales in each one of the countries, and the economic implication of part (ii) is that in country $A$, which has the relatively higher labor market frictions in the differentiated sector, average revenue per entering firm from domestic sales is higher and average revenue per entering firm from export sales is lower than in country $B$. And the last lemma states that there is less entry of firms in the differentiated product industry in the country in which labor market frictions are relatively higher in this sector; a result which is quite intuitive.

Finally, consider the determinants of the number of workers searching for jobs in the differentiated sector, $N_{j}$, and aggregate employment in that sector, $H_{j}$. On the one hand, the wage bill in the differentiated sector, $w_{j} H_{j}$, equals $\omega_{0 j} N_{j}$, because the wage rate is $w_{j}=b_{j}=\omega_{0 j} / x_{j}$ (see (17)) and $x_{j}=H_{j} / N_{j}$ by definition. This implies that aggregate income equals $\omega_{0 j} L$, where income $\omega_{0 j} N_{j}$ is derived from the differentiated sector and income $\omega_{0 j} N_{0}=\omega_{0 j}\left(L-N_{j}\right)$ is derived from the homogeneous sector. On the other hand, the wage bill in the differentiated sector equals the fraction $\beta /(1+\beta)$ of revenue (a result from the bargaining game). Therefore

$$
\omega_{0 j} N_{j}=\frac{\beta}{1+\beta} M_{j}\left(\frac{\delta_{d j}}{\phi_{2}}+\frac{\delta_{x j}}{\phi_{2}}\right)
$$

where $M_{j}\left(\delta_{d j}+\delta_{x j}\right) / \phi_{2}$ is total revenue of country- $j$ firms from domestic sales and exporting. It follows that, once the cutoffs and the numbers of firms are known, this equation determines the number of workers searching for jobs in the differentiated-product industry. ${ }^{28}$ Having solved for $N_{j}$, aggregate employment in the differentiated sector is

$$
H_{j}=x_{j} N_{j}
$$

The remaining $N_{0 j}=L-N_{j}$ workers search for jobs in the homogenous-good sector, with $H_{0 j}=$ $x_{0 j} N_{0 j}$ of them finding employment and generating $H_{0 j}$ units of output of the homogenous good. This completes the description of an equilibrium with incomplete specialization.

\section{Trade, Welfare and Productivity}

In this section we explore channels through which the two countries are interdependent. For this purpose we organize the discussion around two main themes: the impact of a country's labor market

\footnotetext{
${ }^{28}$ Recall that $\omega_{0 j}$ is determined by labor market frictions in the homogeneous sector; see (13).
} 
frictions on its trade partner, and the differential effects of trade impediments on countries with different labor market frictions.

\subsection{Welfare}

We are interested in knowing how labor market rigidities and trade frictions affect welfare, and in particular their differential impact on the welfare of the two countries. Since aggregate spending in country $j, E_{j}$, equals aggregate income, and aggregate income equals $\omega_{0 j} L=a_{0 j}^{-1 / \alpha} L / 2$ (see (13)), the indirect utility function (3) implies that welfare is higher the larger the real consumption index of differentiated products $Q_{j}$ is and the lower the friction in the homogeneous sector $a_{0 j}$ is. We have already shown that $Q_{j}$ is higher in country $B$ (see Lemma 3). It follows that welfare is also higher in $B$ as long as the labor market friction in its homogenous sector, $a_{0 B}$, is not too high relative to that in country $A, a_{0 A}$.

Now combine the formulas for change in the cutoffs (22) with the log-differential of the first equation in (19) to obtain

$$
\frac{\beta-\zeta}{1-\beta} \hat{Q}_{j}=\frac{1}{\Delta}\left[-\delta_{d(-j)}\left(\delta_{x j}+\delta_{d j}\right) \hat{b}_{j}+\delta_{x j}\left(\delta_{x(-j)}+\delta_{d(-j)}\right) \hat{b}_{(-j)}-\delta_{x j}\left(\delta_{d(-j)}-\delta_{x(-j)}\right) \hat{\tau}\right] .
$$

This equation has a number of implications. First, it shows that a reduction in a country's labor market frictions in the differentiated sector, i.e., a decline in $a_{j}$ which reduces $b_{j}$ (see (17)), raises its real consumption index $Q_{j}$ and therefore its welfare, but it reduces the trade partner's welfare. On the other hand, a simultaneous reduction in labor market frictions in the differentiated sectors of both countries at a common rate $\hat{a}_{A}=\hat{a}_{A}$, which implies $\hat{b}_{A}=\hat{b}_{B}$, raises everybody's welfare. ${ }^{29}$ Second, a reduction in a country's labor market frictions at a common rate in both sectors, i.e., a decline in $a_{0 j}$ and $a_{j}$ such that $\hat{a}_{0 j}=\hat{a}_{j}$, does not impact its real consumption index $Q_{j}$ nor the real consumption index of its trade partner $Q_{(-j)}$. As a result, the trade partner's welfare does not change, yet $j$ 's welfare rises because expected income of a worker, $\omega_{0}$, rises (see (3) and (13), and recall that expenditure equals income, $E=\omega_{0 j} L$ ). Third, in view of Lemma 2, a reduction in trade impediments raises welfare in both countries. We summarize these findings in ${ }^{30}$

Proposition 1 (i) A reduction in labor market frictions in country j's differentiated sector raises its welfare and reduces the welfare of its trade partner. (ii) A simultaneous proportional reduction in labor market frictions in the differentiated sectors of both countries raises welfare in both of them. (iii) A reduction in labor market frictions in country $j$ at a common rate in both sectors raises its welfare and does not affect the welfare of its trade partner. (iv) A reduction of trade impediments

\footnotetext{
${ }^{29}$ This follows from the fact that $-\delta_{d(-j)}\left(\delta_{x j}+\delta_{d j}\right)+\delta_{x j}\left(\delta_{x(-j)}+\delta_{d(-j)}\right)=-\beta \Delta /(1-\beta)<0$.

${ }^{30}$ The very last part of the proposition follows from the fact that (26) implies$$
\frac{\beta-\zeta}{1-\beta}\left[\hat{Q}_{j}-\hat{Q}_{(-j)}\right]=-\frac{1}{\Delta}\left[\left(\delta_{d j}+\delta_{x j}\right)\left(\delta_{d(-j)}+\delta_{x(-j)}\right)\left(\hat{b}_{j}-\hat{b}_{(-j)}\right)+\left(\delta_{d(-j)} \delta_{x j}-\delta_{x(-j)} \delta_{d j}\right) \hat{\tau}\right] .
$$

Under these circumstances $\hat{Q}_{j}>\hat{Q}_{(-j)}$ in response to $\hat{\tau}<0$, when $\hat{b}_{j}<\hat{b}_{(-j)}$ (by Lemma 4). 
raises welfare in both countries and $Q_{j}$ rises proportionately more in country $B$, which has relatively lower labor market frictions in the differentiated sector.

The first part of this proposition is intriguing: it states that a country harms the trade partner by reducing its labor market frictions. Moreover, this happens despite the fact that the trade partner $(-j)$ enjoys better terms of trade as a result of improved labor market conditions in country $j$, because $(-j)$ pays lower prices for imported varieties from $j$ and gets access to a larger set of foreign varieties. The reason for this result is that lower labor market frictions in country $j$ 's differentiated sector act like a productivity improvements in this country, which makes foreign firms less competitive and therefore crowds them out from this sector. As a result, fewer foreign firms enter the industry. The entry of domestic firms does not fully compensate foreign consumers for the exit of foreign firms due to the home market effect, so that foreign welfare declines, and this negative welfare effect is larger than the welfare gain from improved terms of trade. ${ }^{31}$

The last part of this proposition establishes that both countries gain from trade, because autarky is attained when $\tau \rightarrow \infty .{ }^{32}$ To emphasize this conclusion, we restate it in

Proposition 2 Both countries gain from trade.

This proposition is interesting, because it is well known that gains from trade are not ensured in economies with nonconvexities and distortions (see Helpman and Krugman (1985)), and in addition to the standard nonconvexities and distortions that exist in models of monopolistic competition our model contains frictions in labor markets. The intuition is that every country gains access to a larger variety choice, and in addition, the differentiated sector - which is too small relative to its first-best size - expands. Together, these effects of trade opening dominate the welfare outcome.

\subsection{Trade Structure}

From Lemma 1 we know that the country with lower relative labor market frictions in the differentiated sector has a lower export cutoff and a higher domestic cutoff; therefore it also has a larger fraction of exporting firms in the differentiated-product sector. In addition, we know that exports

\footnotetext{
${ }^{31}$ Demidova (2008) studies a full employment model with exogenous differences in productivity distributions across countries, and finds that: (a) productivity improvements in one country hurt its trade partner; and (b) falling trade costs benefit disproportionately the more productive country, and may even hurt the less productive country. Our results on labor market frictions are similar to these (except that in our case both countries necessarily gain from falling trade costs), because - not withstanding unemployment-labor market frictions have analogous effects to productivity. We stress that these effects are analogous but not identical, because our cross-country differences in relative labor market frictions are not identical to the differences in productivity in Demidova's paper.

${ }^{32}$ The following is a direct proof of the gains-from-trade argument: We have seen that the domestic cutoff is higher in every country in the trading equilibrium than in autarky. The first equation in (19) then implies that $Q_{j}$ is higher in every country in the trading equilibrium, because this equation also holds in autarky. In addition, in the earlier working paper Helpman and Itskhoki (2008), we show that both countries gain from trade when the difference in labor market institutions is large enough to cause the relatively rigid country to specialize in the production of the homogeneous good. Interestingly, in this case the gains from trade accrue disproportionately to the relatively rigid country, although its level of welfare is always lower than that of the relatively flexible country.
} 
per entering firm equal $\delta_{x j} / \phi_{2}$. Therefore exports of differentiated products from $j$ to $(-j)$ are

$$
X_{j}=M_{j} \frac{\delta_{x j}}{\phi_{2}} .
$$

Lemma 4 states that country $B$ has a larger $\delta_{x j}$ and Lemma 5 states that it has more firms. Therefore $X_{B}>X_{A}$, which implies that $B$ exports differentiated products on net. As a consequence, country $A$ exports homogeneous goods.

As in the standard Helpman-Krugman model of trade in differentiated products, there is intraindustry trade. We can therefore decompose the volume of trade into intra-industry and intersectoral trade. Because trade is balanced, the total volume of trade equals $2 X_{B}$, the volume of intra-industry trade equals $2 X_{A}$, and the share of intra-industry trade equals

$$
\frac{X_{A}}{X_{B}}=\frac{\delta_{x A} M_{A}}{\delta_{x B} M_{B}}
$$

Using this representation we show in the Appendix that the share of intra-industry trade declines in $b_{A} / b_{B}$. These results are summarized in

Proposition 3 Let $b_{A}>b_{B}$. Then: (i) A larger fraction of differentiated-sector firms export in country B. (ii) Country $B$ exports differentiated products on net and imports homogeneous goods. (iii) The share of intra-industry trade is smaller the larger $b_{A} / b_{B}$ is.

That is, as in Davidson and Matusz (1999), labor market frictions impact comparative advantage, and in our case they also impact the share of intra-industry trade. In addition, under Paretodistributed productivity, the model also implies that the volume of trade is larger the larger is the difference in relative hiring costs across countries, $b_{A} / b_{B}$, and the smaller are the trade impediments (see Appendix). These are testable implications of our model.

\subsection{Productivity}

Alternative measures of total factor productivity (TFP) can be used to characterize the efficiency of production. We choose to focus on one such measure - the employment-weighted average of firm-level productivity — which is commonly used in the literature. ${ }^{33}$ In the differentiated sector this measure is

$$
\operatorname{TFP}_{j}=\frac{M_{j}}{H_{j}}\left[\int_{\Theta_{d j}}^{\infty} \Theta^{\frac{1-\beta}{\beta}} h_{d j}(\Theta) d G(\Theta)+\int_{\Theta_{x j}}^{\infty} \Theta^{\frac{1-\beta}{\beta}} h_{x j}(\Theta) d G(\Theta)\right] .
$$

\footnotetext{
${ }^{33}$ This corresponds to the measure analyzed by Melitz (2003) in the appendix. Note that Melitz uses revenue to weight firm productivity levels. However, in equilibrium, revenue is proportional to employment, in which case his and our productivity indexes are the same.
} 
Recall that $q_{z j}(\Theta)=\Theta^{(1-\beta) / \beta} h_{z j}(\Theta)$ for $z=d, x$. Therefore, $T F P_{j}$ equals the output of differentiated products divided by employment in the differentiated sector. ${ }^{34}$

Using (6) and (8)-(10), we can express (27) as

$$
T F P_{j}=\frac{\delta_{d j} \varphi_{d j}+\delta_{x j} \varphi_{x j}}{\delta_{d j}+\delta_{x j}}=\varpi_{d j} \varphi_{d j}+\varpi_{x j} \varphi_{x j},
$$

where $\varpi_{d j}=\delta_{d j} /\left(\delta_{d j}+\delta_{x j}\right)$ is the share of domestic sales in revenue and $\varpi_{x j}$ is the share of exports, i.e., $\varpi_{x j}=1-\varpi_{d j}, j=A, B$. Moreover,

$$
\varphi_{z j} \equiv \varphi\left(\Theta_{z j}\right)=\frac{\int_{\Theta_{z j}}^{\infty} \Theta^{1 / \beta} d G(\Theta)}{\int_{\Theta_{z j}}^{\infty} \Theta d G(\Theta)}, \quad z=d, x,
$$

where $\varphi_{d j}$ represents the average productivity of firms that serve the home market and $\varphi_{x j}$ represents the average productivity of exporting firms. It follows that aggregate productivity equals the weighted average of the productivity of firms that serve the domestic market and the productivity of firms that export, with the revenue shares serving as weights. We show in the Appendix that $\varphi(\cdot)$ is an increasing function. Therefore average productivity is higher among exporters, i.e., $\varphi_{x j}>\varphi_{d j}$.

Expression (28) implies that the cutoffs $\left\{\Theta_{d j}, \Theta_{x j}\right\}$ uniquely determine the $T F P_{j}$ s, because $\varpi_{z j}$ and $\varphi_{z j}$ depend only on the cutoffs. Moreover, since the two cutoffs are linked by the free-entry condition (20), $T F P_{j}$ can be expressed as a function of the domestic cutoff $\Theta_{d j}$. This implies that in a closed economy $T F P_{j}$ is not responsive to changes in labor market frictions, because $\Theta_{d}^{c}$ is uniquely determined by the fixed costs of entry and production and the ex ante productivity distribution.

Productivity $T F P_{j}$ is higher in the trade equilibrium than in autarky, however, because $\varphi\left(\Theta_{x j}\right)>$ $\varphi\left(\Theta_{d j}\right)>\varphi\left(\Theta_{d}^{c}\right)$, and in autarky $\varpi_{x}^{c}=0$. That is, the average productivity of exporters and nonexporters alike is higher in the trade equilibrium than is the average productivity of firms in autarky. In addition, trade reallocates revenue to the exporting firms, which are on average more productive. For both these reasons trade raises $T F P_{j}$. We summarize these results in

Proposition 4 (i) In the closed economy, $\mathrm{TFP}_{j}$ does not depend on labor market frictions. (ii) $\mathrm{TFP}_{j}$ is higher in any trade equilibrium than in autarky.

Next recall that in an open economy a reduction of trade costs raises the domestic cutoff and reduces the export cutoff. In addition, a reduction in country $j$ 's labor market frictions in the differentiated sector raises $\Theta_{d j}$ and $\Theta_{x(-j)}$ and reduces $\Theta_{d(-j)}$ and $\Theta_{x j}$. Finally, a simultaneous

\footnotetext{
${ }^{34}$ An alternative, and potentially more desirable, measure of productivity, would divide output by the number of workers searching for jobs in the differentiated-product sector, $N_{j}$. This measure is always smaller than $T F P_{j}$ by the factor $x_{j}$. It follows that labor market liberalization has an additional positive effect on this measure of productivity as compared to the measure used in the main text. Also note that $T F P_{j}$ measures productivity in the differentiated-product sector only, rather than in the entire economy, and productivity in the homogeneous-product sector is constant given $a_{0 j}$. We discuss in the Appendix a productivity measure that accounts for the compositional effects across sectors.
} 
and proportional decline in both countries' labor market frictions in the differentiated sector (i.e., $\hat{b}_{A}=\hat{b}_{B}<0$ ) leaves all these cutoffs unchanged (see $(22)$ ).

How do changes in labor market frictions impact productivity? In the case in which both countries' labor market frictions decline by the same factor of proportionality, the answer is simple: the $T F P_{j}$ s do not change. As long as productivity is measured with regard to the number of employed workers rather than the number of workers searching for jobs, measured sectoral productivity levels are not sensitive to the absolute levels of $b_{j} \mathrm{~s}$; only the relative levels matter. This result points to a shortcoming of this TFP measure. We nevertheless continue the analysis with this measure, because it is commonly used in the literature.

A shock that raises the domestic cutoff $\Theta_{d j}$ and reduces the export cutoff $\Theta_{x j}$ affects $T F P_{j}$ through three channels. First, the reallocation of revenue from firms that serve the home market to exporters raises the weight on the productivity of exporters, $\varpi_{x j}$, which raises in turn $T F P_{j}$. Second, some least-efficient firms exit the industry, thereby raising the average productivity of firms that sell only in the home market, $\varphi_{d j}$, which raises $T F P_{j}$. Finally, some firms with productivity below $\Theta_{x j}$ begin to export, thereby reducing the average productivity of exporters, $\varphi_{x j}$, which reduces $\operatorname{TFP}_{j} .{ }^{35}$

The presence of the third effect, which goes against the first two, does not enable us to sign the impact of single-country reductions of labor market frictions on productivity; in general, productivity may increase or decrease. The sharp result for the comparison of autarky to trade derives from the fact that, in a move from autarky to trade, the third effect is nil. In the Appendix, we provide sufficient conditions for productivity to be monotonically rising with $\Theta_{d j}$, and therefore declining with $b_{j}$ and $\tau$ and rising with $b_{(-j)}$. In this section, however, we limit our discussion to the case of Pareto-distributed productivity draws, which yields sharp predictions.

Under the assumption of Pareto-distributed productivity, that is, $G(\Theta)=1-\left(\Theta_{\min } / \Theta\right)^{k}$ for $\Theta \geq \Theta_{\min },(28)$ results in (see Appendix):

$$
\widehat{T F P}_{j}=\frac{\delta_{d j}\left(\varphi_{x j}-\varphi_{d j}\right)(1+k-1 / \beta)}{\delta_{d j} \varphi_{d j}+\delta_{x j} \varphi_{x j}} \hat{\Theta}_{d j},
$$

where $k>1 / \beta$ is required for $T F P_{j}$ to be finite, and we therefore assume that it holds, and an increase in $\Theta_{d j}$ is accompanied by a corresponding decrease in $\Theta_{x j}$ in order to satisfy the free-entry condition. As a result, $T F P_{j}$ is higher the higher $\Theta_{d j}$ is (and the lower $\Theta_{x j}$ is). It follows that productivity is higher in country $B$, and a reduction in a country's labor market frictions in the differentiated sector raises its productivity and reduces the productivity of its trade partner. An implication of this result is that the gap in productivity between countries $B$ and $A$ is increasing in $b_{A} / b_{B}$ and therefore in $a_{A} / a_{B}$, their relative labor market frictions in the differentiated sector. These results are summarized in

\footnotetext{
${ }^{35}$ Formally, this decomposition can be represented as $\widehat{T F P}_{j}=\hat{\varpi}_{x j}\left(\varphi_{x j}-\varphi_{d j}\right)+\left(1-\varpi_{x j}\right) \hat{\varphi}_{d j}+\varpi_{x j} \hat{\varphi}_{x j}$ with $\hat{\varpi}_{x j}>0$, $\hat{\varphi}_{d j}>0$ and $\hat{\varphi}_{x j}<0$.
} 
Proposition 5 Let $b_{A}>b_{B}$ and let $\Theta$ be Pareto-distributed with shape parameter $k>1 / \beta$. Then: (i) $T F P_{j}$ is higher in $B$; (ii) a decline in $a_{j}$ raises $T F P_{j}$ and reduces $T F P_{(-j)}$; (iii) a reduction of trade costs $\tau$ raises $T_{F P}$ in both countries.

In other words, total factor productivity is higher in the country with relatively lower labor market frictions in the differentiated sector, and while a reduction of labor market frictions in this sector in any country raises its own total factor productivity, this hurts the total factor productivity of the country's trade partner.

\section{Unemployment}

Before discussing the variation of unemployment across countries with different labor market frictions in Section 5.2, we first examine the determinants of unemployment in a world of symmetric countries.

\subsection{Symmetric Countries}

We study in this section countries with $a_{0 A}=a_{0 B}=a_{0}$ and $a_{A}=a_{B}=a$, so that $b_{A}=b_{B}=b$, in order to understand how changes in the common levels of labor market frictions and the common level of variable trade cost affect unemployment. In such equilibria, the cutoffs $\Theta_{d}$ and $\Theta_{x}$, the consumption index $Q$, the number of entrants $M$, the number of individuals searching for jobs in the differentiated-product sector $N$, the number of workers employed in that sector $H$, and the rate of unemployment $u$ are the same in both countries. We therefore drop the country index $j$ for convenience. From Section 3 we know that two symmetric economies are at the same point on the $F F$ curve in Figure 1 (point $S$ ), the location of this point is invariant to the common level of labor market frictions, and this point is higher the larger $\tau$ is. Moreover, (26) implies that $Q$ is lower the higher are either $b$ or $\tau$. When $b$ is higher as a result of higher frictions in the labor market of the differentiated sector, welfare is lower because $Q$ is lower while aggregate income $E=\omega_{0} L$ is not affected (recall that welfare is given by (3)).

In order to assess the impact of labor market rigidities on unemployment, we need to know their quantitative impact on $Q$. For this reason we use (26) to obtain

$$
\hat{Q}=-\frac{\beta}{\beta-\zeta}\left(\hat{b}+\frac{\delta_{x}}{\delta_{d}+\delta_{x}} \hat{\tau}\right) .
$$

Next combine (23) and (24) to obtain $\omega_{0} N=\beta Q^{\zeta} /(1+\beta)$, which together with the previous equation yields

$$
\hat{N}=-\frac{\beta \zeta}{\beta-\zeta}\left(\hat{b}+\frac{\delta_{x}}{\delta_{d}+\delta_{x}} \hat{\tau}\right)
$$

under the assumption that changes in $b$ are driven by changes in $a$, our measure of labor market frictions in the differentiated sector. In other words, in this analysis we keep constant the level of labor market frictions in the homogeneous sector, $a_{0}$ (below we discuss the case of simultaneous 


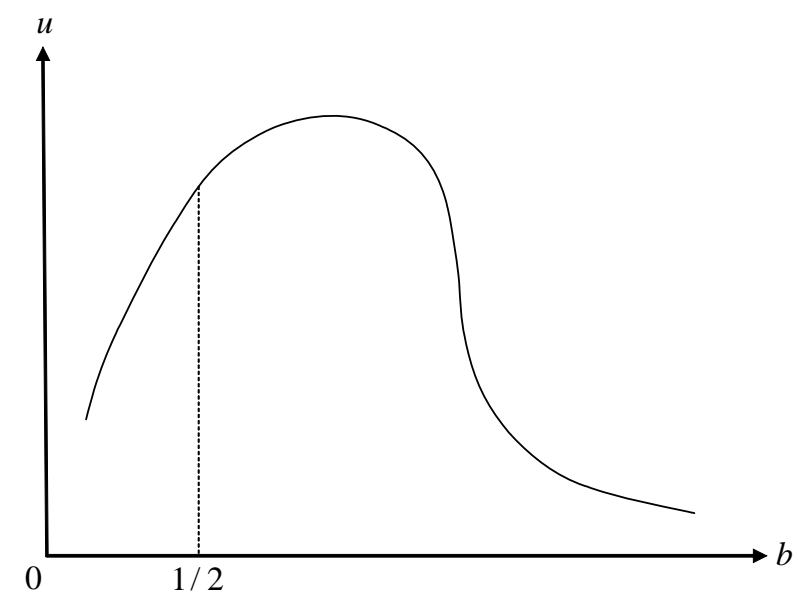

Figure 2: Unemployment in a world of symmetric countries

reductions in labor market frictions in both sectors). Finally, from (17) and (18) together with the formula for $\hat{N}$ we obtain ${ }^{36}$

$$
\operatorname{sign}\{\hat{u}\}=\operatorname{sign}\left\{\left[1-(2 b-1) \frac{\beta \zeta}{\beta-\zeta}\right] \hat{b}-(2 b-1) \frac{\beta \zeta}{\beta-\zeta} \frac{\delta_{x}}{\delta_{d}+\delta_{x}} \hat{\tau}\right\} .
$$

It is evident from this formula that lower frictions in the differentiated sector's labor market (lower b) reduce unemployment if and only if

$$
2 b=\left(\frac{a}{a_{0}}\right)^{\frac{1}{1+\alpha}}<1+\frac{\beta-\zeta}{\beta \zeta},
$$

i.e., if and only if labor market frictions are low in this sector to begin with. This condition is always satisfied when labor market frictions are higher in the homogeneous sector, i.e. $a_{0}>a$. If labor market frictions in the differentiated sector are high, however, and the above inequality is reversed, then a reduction in $a$-and hence in $b$-may raise the rate of unemployment. In fact, the relationship between $b$ and the rate of unemployment has an inverted $U$ shape as depicted in Figure 2.

To understand this result, note that changes in $a$ impact unemployment through two channels: the rate of unemployment in the differentiated sector $1-x$, and the fraction of individuals searching for jobs in this sector $N / L$. Reductions in these labor market frictions raise $x$ and thereby reduce

\footnotetext{
${ }^{36}$ In this derivation we use $b x=b_{0} x_{0}=\omega_{0}$, where $\omega_{0}$ is given in (13) and it does not vary with $a$, the measure of labor market frictions in the differentiated sector. Therefore, $\hat{b}=-\hat{x}$. Also note that $\hat{x}_{0}=0$ since $b_{0} \equiv 1 / 2$. We have

$$
u L \hat{u}=\mathrm{d} N\left(x_{0}-x\right)-N \mathrm{~d} x=x N\left[\left(\frac{x_{0}}{x}-1\right) \hat{N}+\hat{b}\right] .
$$

From $(17), x_{0} / x=\left(a / a_{0}\right)^{1 /(1+\alpha)}=2 b$. Finally, combining these results with the expression for $\hat{N}$, we obtain the result in the text.
} 
the sectoral rate of unemployment. On the other hand, such reductions attract more workers to the differentiated-product sector and thereby reduce the rate of unemployment if and only if the sectoral rate of unemployment is higher in the homogeneous sector (i.e., $x<x_{0}$ ). When $a_{0}>a$ the sectoral rate of unemployment is higher in the homogenous sector and both channels lead to a reduction in the rate of unemployment. On the other hand, when $a>a_{0}$, the two channels conflict, and the latter, i.e., the reallocation of labor toward the differentiated sector, dominates when labor market frictions are high. ${ }^{37}$

Next consider a proportional reduction in both sectors' labor market frictions, i.e., $\hat{a}_{0}=\hat{a}<0$. This has no effect on the search cost $b$ and does not impact the real consumption index $Q$ (see (17) and (26)). However, it reduces expected income $\omega_{0}$ : from (13), $\hat{\omega}_{0}=-\hat{a} / \alpha$. It therefore follows from $\omega_{0} N=\beta Q^{\zeta} /(1+\beta)$ that $\hat{N}=\hat{a} / \alpha$, and it follows from (17) that $\hat{x}=\hat{x}_{0}=-\hat{a} / \alpha$. Using these expressions, and $N_{0}+N=L$, the unemployment formula (18) implies that $\operatorname{sign}\{\hat{u}\}=\operatorname{sign}\{\hat{a}\}$. In other words, a reduction of labor market frictions at a common rate in both sectors reduces the rate of unemployment. Note that this sort of change in labor market frictions impacts unemployment through two channels, which may operate in opposite directions. On one hand, it raises tightness in each sector's labor market, thereby reducing both sectoral rates of unemployment. On the other hand, it leads to a reallocation of workers from the differentiated to the homogeneous sector. If the sectoral rate of unemployment is higher in the differentiated sector, this reduces the rate of unemployment. But if the sectoral rate of unemployment is lower in the differentiated sector, this raises the rate of unemployment. Nevertheless, the composition effect is dominated by the sectoral effects. ${ }^{38}$

Finally, consider changes in trade impediments. As the formula for the sign of changes in the rate of unemployment shows, a lower trade cost $\tau$ raises the rate of unemployment if and only if $b>1 / 2$ (i.e., $a>a_{0}$ ). ${ }^{39}$ In this case the impact on unemployment operates only through the reallocation of labor across sectors, because sectoral unemployment rates do not change. In particular, more workers search for jobs in the differentiated sector when $\tau$ declines, and therefore aggregate unemployment rises when the differentiated sector has higher sectoral unemployment and aggregate unemployment falls when the differentiated sector has lower sectoral unemployment. Since the lowering of trade costs raises welfare, this means that welfare and unemployment may respond in opposite directions to changes in trade costs.

We summarize the main findings of this section in

Proposition 6 In a symmetric world economy: (i) reductions in labor market frictions in the differentiated sectors at the same rate in both countries reduce aggregate unemployment if and only if $a<a_{0} \cdot[1+(\beta-\zeta) / \beta \zeta]^{1+\alpha}$; (ii) reductions in labor market frictions at a common rate in both

\footnotetext{
${ }^{37}$ It can also be shown that in the symmetric case lower $a$ lead to increased entry of firms $M$, an increase in $N$ proportionately to $M$, and a more than proportional increase in employment $H$.

${ }^{38}$ From (18) and $N_{0}+N=L$ we obtain $u L \hat{u}=-N_{0} x_{0} \hat{x}_{0}-N x \hat{x}+\left(x_{0}-x\right) N \hat{N}$, where the first two expressions on the right-hand sided represent the sectoral effects and the third represents the composition effect. Since $\hat{x}=\hat{x}_{0}=$ $-\hat{N}=-\hat{a} / \alpha$, the sectoral effects dominate.

${ }^{39}$ The effect of a reduction in trade costs on unemployment is larger the larger is the share of trade in the sector's revenue, i.e., the larger is $\delta_{x j} /\left(\delta_{d j}+\delta_{x j}\right)$. When the economies are nearly closed, this effect is very small.
} 
sectors and both countries reduce aggregate unemployment; (iii) reductions in trade impediments raise aggregate unemployment if and only if $a>a_{0}$.

An intriguing result is that lower trade barriers may raise unemployment. Lower trade costs make exporting more profitable in the differentiated-product sector. Moreover, the tightness in its labor market is not affected by falling trade costs. This increases demand for labor in the differentiated sector and leads to reallocation of workers towards this sector. Under these circumstances, the sectoral unemployment rates remain the same, but the aggregate unemployment rate may increase or decrease due to the compositional effect across sectors. ${ }^{40}$ The direction of this effect depends on whether the differentiated sector has a higher or lower unemployment rate.

Also note that unemployment can increase or decrease when welfare rises. That is, depending on the nature of the disturbance and the initial labor market frictions, unemployment and welfare can move in the same or in opposite directions. For this reason changes in unemployment do not necessarily reflect changes in welfare. This results from the standard property of search and matching models, in which unemployment is a productive activity which leads to creation of productive matches. Under these circumstances an expansion of the high-wage $\backslash$ high-unemployment sector results in higher unemployment, but may also raise welfare.

\subsection{Asymmetric Countries}

We address in this section the impact of trade and labor market frictions on unemployment when the two countries are not symmetric. We first discuss some analytical results and then turn to numerical examples to illustrate the key mechanisms and various special cases.

In our working paper, Helpman and Itskhoki (2008), we provide analytical results for countries that are nearly symmetric, in the sense that they have no labor market frictions in the homogeneous sector and the difference between their labor market frictions in the differentiated sector is very small. Under these circumstances $b_{A}>b_{B}$ implies that: (i) a reduction in a country's labor market frictions reduces the rate of unemployment in its trade partner, yet it reduces home unemployment if and only if the initial levels of friction in the labor markets are low; and (ii) country $B$ has a lower rate of unemployment if and only if the levels of labor market frictions are low to begin with. Evidently, a country's level of unemployment depends not only on its own labor market frictions but also on those of its trade partner. Moreover, lower domestic labor market frictions do not guarantee lower unemployment relative to the trade partner, unless the frictions in both labor markets are low. As a result, one cannot infer differences in labor market rigidities from observations of unemployment rates. Richer results obtain with large labor market frictions, as we show below.

\footnotetext{
${ }^{40}$ See Felbermayr, Prat and Schmerer (2008) for a one-sector search model in which trade causes an increase in sectoral labor market tightness by reducing the real cost of vacancies, but naturally has no compositional effect.
} 
For our numerical illustrations we use a Pareto distribution of productivity levels,

$$
G(\Theta)=1-\left(\frac{\Theta_{\min }}{\Theta}\right)^{k}, \text { for } \Theta \geq \Theta_{\min } \text { and } k>2 .
$$

As is well known, the shape parameter $k$ controls the dispersion of $\Theta$, with smaller values of $k$ representing more dispersion. It has to be larger than two for the variance of productivity to be finite. We show in the Appendix how the equilibrium conditions are simplified when productivity is distributed Pareto, and these equations are used to generate our numerical examples. One convenient implication of the Pareto assumption is that condition (11) implies $\delta_{d j}+\delta_{x j}=k f_{e}$, and therefore aggregate revenue in the differentiated sector is independent of labor market frictions and is the same in both countries. For the simulations we also assume that $a_{0 A}=a_{0 B}=a_{0}$, so that labor market frictions in the homogenous sector are the same in both countries, as a result of which expected income of workers, $\omega_{0 j}$, is also the same in both countries, i.e., $\omega_{0 A}=\omega_{0 B}=\omega_{0}$. In addition, we assume that $a_{A}>a_{B}>a_{0}$, so that labor market frictions are larger in the differentiated sectors of both countries than in their homogeneous sectors, and particularly so in country $A$. This implies $b_{A}>b_{B}>1 / 2$.

Combining (23) and (24), we obtain the following expression for global revenues generated in the differentiated sector:

$$
Q_{A}^{\zeta}+Q_{B}^{\zeta}=\frac{1}{\phi_{2}}\left[M_{A}\left(\delta_{d A}+\delta_{x A}\right)+M_{B}\left(\delta_{d B}+\delta_{x B}\right)\right]=\frac{1+\beta}{\beta} \omega_{0}\left(N_{A}+N_{B}\right)
$$

Therefore, whenever $Q_{A}^{\zeta}+Q_{B}^{\zeta}$ rises, the world-wide allocation of workers to the differentiated sector, $N_{A}+N_{B}$, must also increase. ${ }^{41}$ Next note that Proposition 1 establishes that a reduction in trade costs raises $Q_{j}$ in both countries. Therefore, the above discussion implies that a reduction in trade costs increases $N_{A}+N_{B}$. In the Appendix we also show that $N_{A} / N_{B}$ declines with reductions in $\tau$ when $b_{A}>b_{B}$. This then implies that $N_{B}$, the number of job-seekers in the differentiated sector of country $B$, necessarily increases. Since a fall in $\tau$ does not affect sectoral labor market tightness, we conclude that a reduction in trade costs increases unemployment in country $B$, which has lower labor market frictions in the differentiated sector. The effect on $N_{A}$ and hence on the unemployment rate in country $A$ is ambiguous, as we illustrate below.

The intuition behind this result is the following. Lower trade impediments increase the global size of the differentiated sector, which features increasing returns to scale and love of variety. As a result, the country with a more flexible labor market, which has a competitive edge in this sector, becomes more specialized in differentiated products. That is, the number of entering firms, employment, and the number of job-seekers in the differentiated sector, all increase in country $B$.

\footnotetext{
${ }^{41}$ Note that this result does not rely on the Pareto assumption. Under the Pareto assumption, however, we additionally have $Q_{A}^{\zeta}+Q_{B}^{\zeta}=k f_{e}\left(M_{A}+M_{B}\right) / \phi_{2}$, so that the total number of entrants into the differentiated sector must also increase. Moreover, in the Appendix we show that in this case $\omega_{0} N_{j} / M_{j}=\beta k f_{e} /(1-\beta)$. That is, the number of workers searching for jobs in the differentiated sector relative to the number of firms depends on expected income $\omega_{0}$, but does not depend on the trade cost or labor market frictions in the differentiated sector.
} 


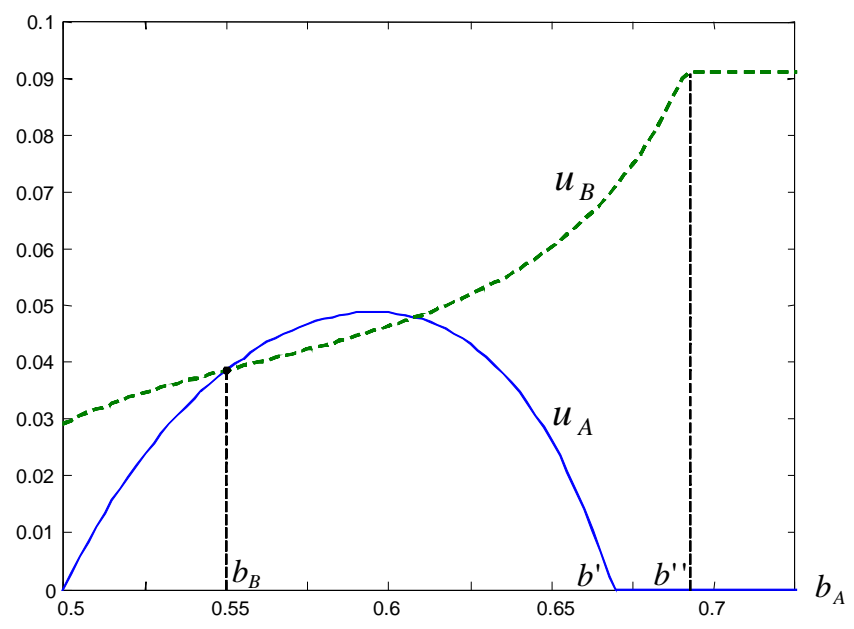

Figure 3: Unemployment as a function of $b_{A}$ when $b_{B}$ is low $\left(b_{B}=0.55\right.$ and $\left.\tau=1.1\right)$

This compositional shift leads to a higher rate of unemployment in this country, because the sectoral rate of unemployment is higher in the differentiated sector. Finally, the reallocation of labor in country $A$ may shift in either direction, depending on how strong the comparative advantage is (see below).

Figure 3 depicts the response of unemployment rates to variation in country $A$ 's labor market frictions $a_{A}$, which changes monotonically $b_{A}$; the rising broken-line curve represents country $B$ and the hump-shaped solid-line curve represents country $A .{ }^{42}$ Country $B$ has $b_{B}=0.55>1 / 2$, and therefore the two countries have the same rate of unemployment when $b_{A}=0.55$. As $b_{A}$ rises, country $A$ becomes more rigid. This raises initially the rate of unemployment in both countries, but $B$ 's rate of unemployment remains lower for a while. At some point, however, the rate of unemployment reaches a peak in country $A$, and it falls for further increases in $b_{A}$. As a result, the two rates of unemployment become equal again, after which further increases in rigidity in country $A$ raise the rate of unemployment in country $B$ and reduce it in country $A$, so that the rate of unemployment is higher in country $B$ thereafter. The mechanism that operates here is that once the labor market frictions become high enough in country $A$, the contraction of the differentiated-product sector leads to overall lower unemployment in $A$ despite the fact that its sectoral unemployment rate is high. When $b_{A}$ is very high the sectoral unemployment rate is very high, but no individuals search for jobs in this sector, as a result of which there is no unemployment at all. This explains the hump in $A$ 's curve. Note that in the range in which the rate of unemployment falls in country $A$ the rate of unemployment keeps rising in country $B$. The reason is that there is no change in market tightness in country $B$ and its differentiated-product sector becomes more competitive the more rigid the labor market becomes in $A$. As a result the differentiated sector attracts more and more workers in country $B$, which raises its rate of unemployment. The monotonic impact of country

\footnotetext{
${ }^{42}$ In Figures 3-4 we use the following parameters: $m_{0}=2 v_{0}=1, f_{x}=3, f_{d}=1, f_{e}=0.5, k=2.5, \beta=0.75$, $\zeta=0.5$ and $L=0.1$.
} 


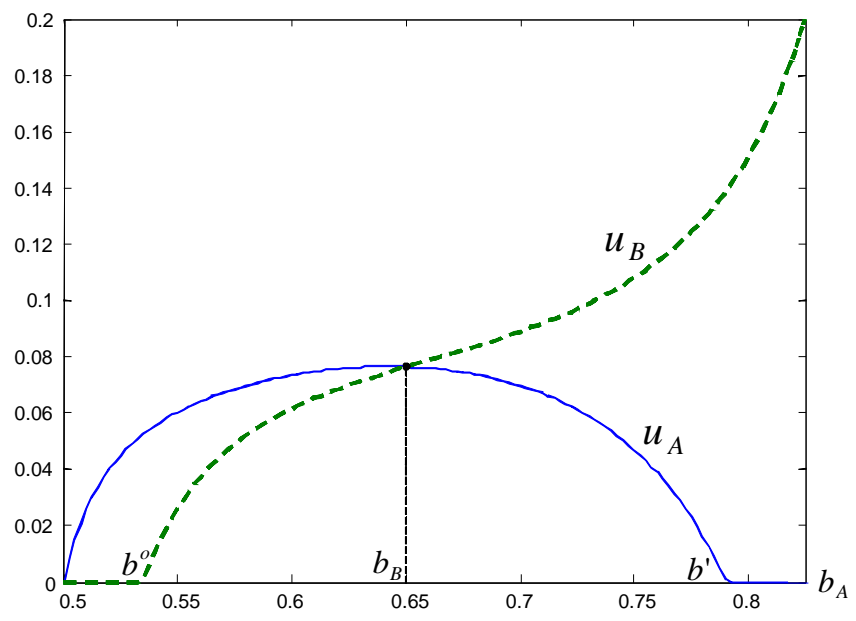

Figure 4: Unemployment as a function of $b_{A}$ when $b_{B}$ is high $\left(b_{B}=0.65\right.$ and $\left.\tau=1.1\right)$

$A$ 's labor market rigidities on the unemployment rate in $B$ holds globally, and not only around the symmetric equilibrium. ${ }^{43}$

Figure 4 is similar to Figure 3, except that now the level of labor market frictions in country $B$ is higher, i.e., $b_{B}=0.65>1 / 2$, and therefore the two curves intersect at $b_{A}=0.65$. Moreover, starting with a symmetric world that has these higher labor market rigidities, increases in $b_{A}$ always raise unemployment in $B$ and reduce unemployment in $A$. As a result, country $A$ has lower unemployment when $b_{A}>b_{B}$ and higher unemployment when $b_{A}<b_{B}$. That is, in this case a more rigid country always has a lower unemployment rate when it specializes (incompletely) in the low-unemployment sector.

A comparison between Figures 3 and 4 demonstrates the importance of the overall level of labor market rigidities for unemployment outcomes. When labor market frictions are high, a relatively more flexible country always has a higher rate of unemployment. Moreover, the rates of unemployment in the two countries move in opposite directions as labor market frictions change in either one of the countries. In contrast, when labor market rigidities are low and the difference in labor market frictions across countries is not large, the rate of unemployment is lower in a more flexible country and the rates of unemployment in both countries co-move in response to changes in labor market frictions.

The next three figures depict variations in unemployment in response to trade frictions, in the form of variable trade $\operatorname{costs} \tau$ : Figure 5 for the case of low frictions in labor markets, Figure 6 for the case in which frictions are low in country $B$ but high in $A$, and Figure 7 for the case in which frictions are high in both countries. ${ }^{44}$ In all three cases unemployment rises in $B$ and falls in $A$

\footnotetext{
${ }^{43}$ In Figures 3-4, country $A$ specializes in the homogeneous good when $b_{A} \geq b^{\prime}$; in Figure 4 , country $B$ specializes in the homogeneous good when $b_{A} \leq b^{\circ}$; in Figure 3 country $B$ specializes in the differentiated good for $b_{A} \geq b^{\prime \prime}$.

${ }^{44}$ In Figures 5-7 we use the following parameters: $m_{0}=2 v_{0}=1, f_{x}=5, f_{d}=1, f_{e}=0.5, k=2.5, \beta=0.75$, $\zeta=0.5$, and $L=0.1$.
} 


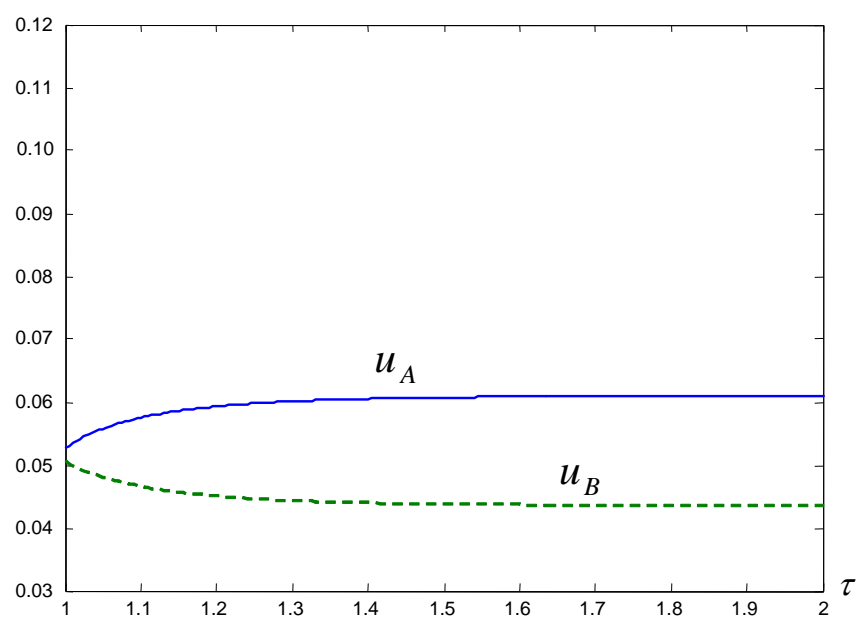

Figure 5: Unemployment as a function of $\tau$ when $b_{A}$ and $b_{B}$ are low $\left(b_{A}=0.6\right.$ and $\left.b_{B}=0.56\right)$

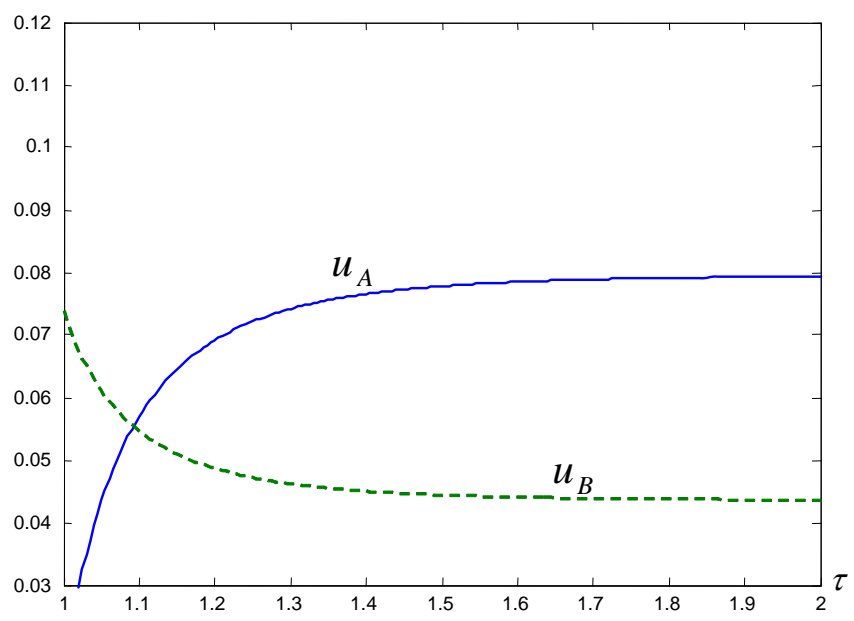

Figure 6: Unemployment as a function of $\tau$ when $b_{A}$ is high and $b_{B}$ is low $\left(b_{A}=0.68\right.$ and $\left.b_{B}=0.56\right)$ 


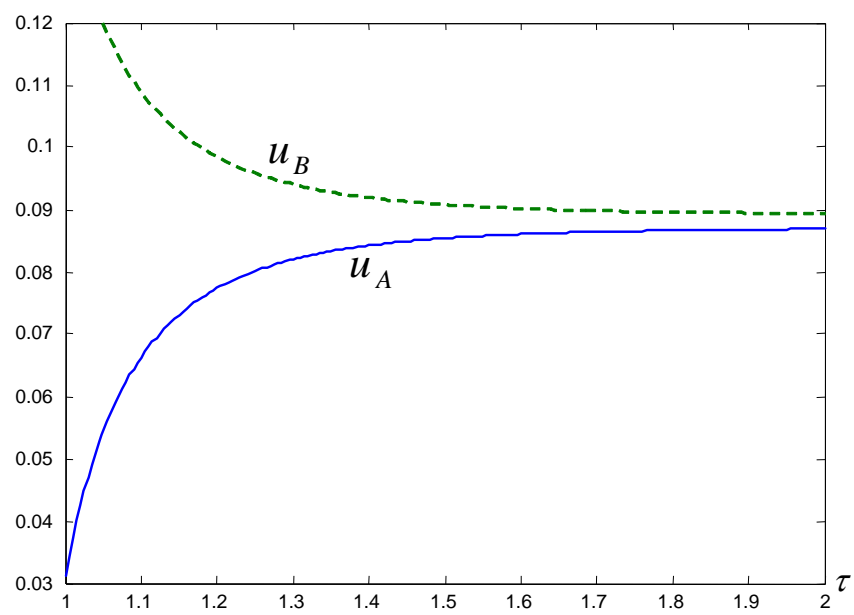

Figure 7: Unemployment as a function of $\tau$ when $b_{A}$ and $b_{B}$ are high $\left(b_{A}=0.95\right.$ and $\left.b_{B}=0.8\right)$

when trade frictions decline. ${ }^{45}$ Nevertheless, the rate of unemployment is not necessarily higher in $A$. In particular, unemployment is always higher in $A$ when frictions in labor markets are low in both countries, yet unemployment is always higher in $B$ when frictions in labor markets are high in both countries. In between, when labor market frictions are low in $B$ and high in $A$, the relative rate of unemployment depends on trade impediments; it is lower in $A$ when the trade frictions are low and lower in $B$ when the trade frictions are high. This shows that labor market frictions interact with trade impediments in shaping unemployment.

\section{Firing Costs and Unemployment Benefits}

Our analysis has focused on search and matching as the main frictions in labor markets, and we used $a_{0 j}=2 v_{0 j} / m_{0 j}^{1+\alpha}$ and $a_{j}=2 v_{0 j} / m_{0 j}^{1+\alpha}$ as measures of labor market rigidity. Evidently, in this specification rigidity in a sector's labor market is higher if either it is more costly to post vacancies in this sector or the matching process is less efficient in it.

We can also incorporate firing costs and unemployment benefits as additional sources of labor market rigidity. These labor market policies are widespread and they differ greatly across countries. But note that governments can also influence search and matching costs by facilitating the flow of information about job vacancies and about unemployed workers. Moreover, in some countries there are government agencies that directly assign unemployed workers to firms, and workers need to try these jobs in order to be eligible for unemployment benefits. In other words, government policies can influence not only firing costs and unemployment benefits, but also our measures of labor market frictions, $a_{0 j}$ and $a_{j}$, which were analyzed above.

\footnotetext{
${ }^{45}$ This pattern is not general. As we know, in the symmetric case lower trade impediments raise unemployment in both countries, which is also the case when countries are nearly symmetric. We can also provide examples in which the rigid country has a hump in its rate of unemployment as trade frictions vary.
} 
In order to save space, we briefly describe in this section results of a formal analysis conducted in our working paper, Helpman and Itskhoki (2008), under the simplifying assumption that there is full employment in the differentiated sector. This analysis can be extended to allow for labor market frictions in the homogenous-good sector, as in the earlier sections of the current paper.

With firing costs and unemployment benefits, $\left(x_{j}, b_{j}\right)$ remains a sufficient statistic for labor market frictions, with $b_{j}$ reinterpreted to represent the overall effective labor cost for a differentiatedsector firm, while the definition of $x_{j}$ does not change; it remains the same measure of labor market tightness in the differentiated sector. Importantly, the effects of $x_{j}$ and $b_{j}$ on the equilibrium outcomes described in Sections 3-5 do not change, except for the qualification of welfare effects to be discussed below.

Firing costs operate similarly to matching frictions, yielding a type of equivalence between the hiring and firing costs. Specifically, higher firing costs reduce labor market tightness $x_{j}$ and increase the effective labor cost $b_{j}$. Moreover, as long as unemployment benefits are not too high (see below), the effects of firing costs on welfare, trade patterns, productivity and unemployment in trading economies, are the same as those of matching frictions. That is, all the earlier results of this paper extend to the case in which there are positive firing costs in addition to matching frictions.

Higher unemployment benefits always reduce equilibrium labor market tightness $x_{j}$, but they may increase or decrease the effective labor cost $b_{j}$. The intuition for this result is that unemployment benefits provide unemployment insurance to the workers on the one hand and a better outside option in the wage bargaining game on the other. Because higher unemployment benefits provide better unemployment insurance, workers are willing to search for jobs in a less tight labor market, with a higher sectoral rate of unemployment. This effect reduces the cost of hiring for firms. On the other side the better outside option of workers at the wage bargaining stage improves their bargaining position and increases the effective cost of labor to firms. Either one of these effects can dominate. Therefore $b_{j}$ may rise or decline in response to higher unemployment benefits. When $b_{j}$ decreases, it leads to an expansion of the differentiated sector, which raises welfare. But because unemployment benefits need to be financed by (lump-sum) taxes, the additional taxes required to finance higher unemployment benefits reduce disposable income and hurt welfare. Therefore on net welfare may rise or decline, but it definitely rises in response to a small rise in unemployment benefits that reduces $b_{j}$ when the initial level of these benefits is small. ${ }^{46}$

We also show that firing costs and unemployment benefits not withstanding, international trade may raise unemployment in both countries. The reason is that trade attracts more workers to the differentiated sector without affecting sectoral labor market tightness. Therefore, when this sector has the lower labor market tightness, trade increases aggregate unemployment.

\footnotetext{
${ }^{46}$ Severance pay affects labor costs similarly to unemployment benefits, except that it has no impact on disposable income.
} 


\section{Concluding Comments}

We have studied the interdependence of countries that trade homogeneous and differentiated products, and whose labor markets are characterized by search and matching frictions. Variation in labor market frictions and the interactions between trade impediments and labor market rigidities generate rich patterns of unemployment. For example, lower frictions in a country's labor markets do not ensure lower unemployment, and unemployment and welfare can both rise in response to a policy change.

Contrary to the complex patterns regarding unemployment, the model yields sharp predictions about welfare. In particular, both countries gain from trade. Moreover, changes in one country's labor market frictions can differentially impact welfare of the trade partners. For example, reducing a country's frictions in the labor market of the differentiated sector raises competitiveness of its firms. This improves the foreign country's terms of trade, but also crowds out foreign firms from the differentiated-product sector. As a result, welfare rises at home and declines abroad, because the terms-of-trade improvement in the foreign country is outweighed by the decline in the competitiveness of its firms. Nevertheless, a common reduction in labor market frictions in the differentiated sectors raises welfare in both countries. These results contrast with the implications of models of pure comparative advantage, in which movements in the terms of trade dominate the outcomes. ${ }^{47}$

We also show that labor market frictions confer comparative advantage, and that differences in these labor market characteristics shape trade flows. In particular, the country with relatively lower labor market frictions in the differentiated sector exports differentiated products on net and imports homogeneous goods. Moreover, the larger the difference in these relative frictions, the lower is the share of intra-industry trade. These are testable implications about trade flows and international patterns of specialization.

In addition, we show that trade raises total factor productivity in the differentiated-product sectors of both countries, while productivity does not change in the homogeneous sector. And productivity is higher in the country with relatively lower labor market frictions in the differentiated sector.

An important conclusion from our analysis is that simple one-sector macro models that ignore compositional effects may be inadequate for assessing labor market frictions, and especially so in a world of integrated economies. Moreover, a focus on terms-of-trade as the major channel of the international transmission of shocks misses the impact of competitiveness, which can dominate economic outcomes.

\footnotetext{
${ }^{47}$ See, for example, Brügemann (2003) and Alessandria and Delacroix (2008). The former examines the support for labor market rigidities in a Ricardian model in which the choice of regime impacts comparative advantage. The latter analyzes a two-country model with two goods, in which every country specializes in a different product and governments impose firing taxes. The authors find that a coordinated elimination of these taxes yields welfare gains for both counties, yet no country on its own has an incentive to do it.
} 


\section{Appendix}

\section{A An alternative specification with homothetic preferences}

We consider here an alternative specification of the model, with CRRA-CES preferences instead of quasilinear preferences used in the main text, leaving the rest of the setup unchanged. The expected utility is $\mathbb{U}=\mathbb{E} \mathcal{C}^{1-\sigma} /(1-\sigma)$, where $\mathbb{E}$ is the expectations operator, $\sigma \in[0,1)$ is the relative risk aversion coefficient and $\mathcal{C}$ is a CES bundle of homogenous and differentiated goods:

$$
\mathcal{C}=\left[\vartheta^{1-\zeta} q_{0}^{\zeta}+(1-\vartheta)^{1-\zeta} Q^{\zeta}\right]^{1 / \zeta}, \quad \zeta<\beta, \quad 0<\vartheta<1 .
$$

The ideal price index associated with this consumption bundle is

$$
\mathcal{P}=\left[\vartheta+(1-\vartheta) P^{\frac{-\zeta}{1-\zeta}}\right]^{-\frac{1-\zeta}{\zeta}},
$$

where the price of the homogenous good $p_{0}$ is again normalized to one and $P$ is the price of the differentiated product in terms of the homogenous good.

The demand for homogenous and differentiated goods is given by

$$
\begin{aligned}
q_{0} & =\vartheta \mathcal{P}^{\zeta /(1-\zeta)} E=\frac{\vartheta E}{\vartheta+(1-\vartheta) P^{\frac{-\zeta}{1-\zeta}}}, \\
Q & =(1-\vartheta)\left(\frac{P}{\mathcal{P}}\right)^{\frac{-1}{1-\zeta}} \frac{E}{\mathcal{P}}=\frac{(1-\vartheta) P^{\frac{-1}{1-\zeta}} E}{\vartheta+(1-\vartheta) P^{\frac{-\zeta}{1-\zeta}}},
\end{aligned}
$$

where $E$ is expenditure in units of the homogenous good. Using these demand equations, we derive the indirect utility function

$$
\mathbb{V}=\frac{1}{1-\sigma} \mathbb{E}\left(\frac{E}{\mathcal{P}}\right)^{1-\sigma}
$$

Since $\mathcal{P}$ is increasing in $P$, the indirect utility is falling in $P$ for a given $\mathbb{E} E^{1-\sigma}$. Also $Q$ is decreasing in $P$.

Next, the demand level for differentiated varieties is

$$
D \equiv Q P^{\frac{1}{1-\beta}}=\frac{(1-\vartheta) P^{\frac{\beta-\zeta}{(1-\beta)(1-\zeta)}} E}{\vartheta+(1-\vartheta) P^{\frac{-\zeta}{1-\zeta}}},
$$

which increases in $P$ given $\beta>\zeta$. It proves useful to introduce the aggregate revenue variable

$$
R \equiv P Q=D^{1-\beta} Q^{\beta}=\frac{(1-\vartheta) P^{\frac{-\zeta}{1-\zeta}} E}{\vartheta+(1-\vartheta) P^{\frac{-\zeta}{1-\zeta}}},
$$

which, like $Q$ and opposite to $D$, decreases in $P$. Note that with homothetic utility, demands and revenues are linear in income, $E$, which allows for simple aggregation. Specifically, in the expressions above $E$ can be interpreted as aggregate income equal to $E=\omega_{0}(L-N)+w x N$ and we normalize $L=1$ since under homothetic demand it is without loss of generality.

Most of the remaining derivation of equilibrium conditions remains unchanged, with $D$ replacing $Q^{-(\beta-\zeta) /(1-\beta)}$ in the text. Specifically, after this substitution the free entry condition and zero profit conditions are unchanged, which allows us to solve for equilibrium cutoffs and equilibrium $D$ 's in the same manner as in the 
text. Qualitatively all the relationships still hold, except that now instead of $Q$ as the sufficient statistic for welfare and demand level it is more convenient to express all aggregate variables as functions of $P$. Additionally, $R=P Q$ replaces $Q^{\zeta}$ in the expressions for $M$ and $N$.

One block of the equilibrium system that changes is the indifference conditions of workers between sectors which now becomes

$$
x_{0} w_{0}^{1-\sigma}=x w^{1-\sigma} .
$$

The wage rate in the homogenous sector is still $w_{0}=b_{0}=1 / 2$ and equations characterizing $x_{0}$ and $\omega_{0}=x_{0} w_{0}$ (12) and (13) still hold. The wage rate in the differentiated sector is still $w=b$, where $b=a x^{\alpha}$ is the hiring cost (and similarly $b_{0}$ ). As a result, when $a=a_{0}$, we have $b=b_{0}=1 / 2, x=x_{0}$ and $w=w_{0}$ and $a>a_{0}$ implies $b>b_{0}=1 / 2, x<x_{0}$ and $w>w_{0}$. In the latter case there is a risk premium for searching for a job in the differentiated sector so that $x w>\omega_{0}=x_{0} w_{0}$ with the size of risk premium depending on risk aversion $\sigma$. Finally, since all workers are indifferent between searching for a job in the two sectors, we have for every worker $\mathbb{E} E^{1-\sigma}=x_{0} w_{0}^{1-\sigma}=x_{0}(1 / 2)^{1-\sigma}$, which is pinned down by the labor market friction in the homogenous sector, $a_{0}$. Therefore, holding $a_{0}$ constant, the welfare in the economy depends only on the price level, $\mathcal{P}$, which in turn is determined by the price of the differentiated good, $P$.

Note that with homothetic preferences and $0 \leq \sigma<1$, we have dropped the family interpretation. In this case, the structure of demand and indirect utility does not change if the worker becomes unemployed, and aggregation is straightforward. ${ }^{48}$ As a result, this specification can be used to analyze issues such as the ex-post income distribution and winners and losers from policy reforms.

Without showing the explicit derivation (which follows the same steps as in the text), we provide as an illustration a few comparative statics results for the symmetric open economies with homothetic preferences. Specifically, we consider proportional labor market deregulation in the differentiated sector of both countries (i.e., a decrease in $a$ holding $a_{0}$ constant). We have $\hat{D}=\beta /(1-\beta) \hat{b}$, so that, as before, $P$ decreases and $Q$ and $R$ increase as $b$ falls. This also implies an increase in welfare.

As before, we can express the total wage bill in the differentiated sector as

$$
b H=\frac{\beta}{1+\beta} R=\frac{\beta}{1+\beta} M\left(\delta_{d}+\delta_{x}\right) / \phi_{2},
$$

where the $\delta_{z} \mathrm{~s}$ are average revenues per entering firm as defined in the text. We still have $H=x N$. Using $x b^{1-\sigma}=x_{0}(1 / 2)^{1-\sigma}$, we have the expression for the number of workers searching for a job in the differentiated sector:

$$
N=\frac{\beta}{1+\beta} \frac{R}{b^{\sigma} x_{0}(1 / 2)^{1-\sigma}}
$$

Since $R$ is decreasing in $b$, we have that $N$ decreases in $b$ as before. As a result, there are still two opposing effects on the unemployment rate when $x<x_{0}$ : $\operatorname{sign}\{\hat{u}\}=\operatorname{sign}\left\{(1-\sigma) \hat{b}+\left(x_{0} / x-1\right) \hat{N}\right\}$. The change in the unemployment rate is again ambiguous: it still falls if the initial labor market friction is low enough and increases otherwise. These results are qualitatively the same as those derived in the text under quasi-linear preferences.

Additionally, we can discuss now ex post inequality. When $b>b_{0}$, a fall in $b$ increases $x$ and reduces $w$, which both lead to lower ex-post inequality. At the same time it increases $N$ which may increase or reduce inequality depending on the initial size of the differentiated sector. It follows that the comparative statics for inequality are ambiguous in the same way as those for the rate of unemployment. For discussion of these and other issues see Helpman, Itskhoki and Redding (2009) in a related but different model.

\footnotetext{
${ }^{48}$ In the case of $\sigma \geq 1$, we need to introduce unemployment benefits in order to dispense with the family risk-sharing.
} 


\section{B Conditions for Incomplete Specialization}

We derive here a limit on $b_{A} / b_{B}$ which secures an equilibrium in which both countries are incompletely specialized. When this condition is violated, the country with a relatively more rigid labor market (higher $b$ ) specializes in the production of the homogenous good. Throughout we assume for concreteness that $A$ is the relatively more rigid country, so that $b_{A} / b_{B} \geq 1$. We assume that $L$ is large enough in both countries so that both countries always produce the homogenous good. Following the main text, we analyze only equilibria with $\Theta_{x j}>\Theta_{d j}>\Theta_{\min }$, so that not all producing firms export and there are also firms that exit. As shown in the text, this requires $f_{x}>f_{d}$ which we assume holds.

Given $b_{A}>b_{B}$, incomplete specialization implies that there is positive entry of firms in the differentiated sector of country $A$, i.e., $M_{A}>0$. Equation (23) in the text implies that $M_{A}=0$ whenever

$$
\delta_{d B}\left(\frac{Q_{A}}{Q_{B}}\right)^{\zeta} \leq \delta_{x B}
$$

When this condition is satisfied with equality we also find, using (19), that

$$
\delta_{d B}\left[\frac{\Theta_{x B}}{\Theta_{d B}} \frac{f_{d}}{f_{x}} \tau^{\frac{-\beta}{1-\beta}}\right]^{\zeta \frac{1-\beta}{\beta-\zeta}}=\delta_{x B} .
$$

Note that this relationship is a (generally nonlinear) upward-sloping curve in $\left(\Theta_{d B}, \Theta_{x B}\right)$-space, lying between the $45^{\circ}$-line and $\Theta_{x B}=\Theta_{d B} \tau^{\beta /(1-\beta)} f_{x} / f_{d}$ (i.e., the equilibrium condition when $\left.b_{A}=b_{B}\right) .{ }^{49}$

We can now prove the following

Lemma 6 Let $\tau>1$ and $b_{A}>b_{B}$. Then there exists a unique $\bar{b}(\tau)>1$, with $\bar{b}^{\prime}(\tau)>0$, such that (30) holds for $b_{A} / b_{B}=\bar{b}(\tau)$. For $b_{A} / b_{B}<\bar{b}(\tau)$, there is incomplete specialization in equilibrium so that $M_{A}>0$. For $b_{A} / b_{B} \geq \bar{b}(\tau)$, country $A$ specializes in the homogenous good so that $M_{A}=0$.

Proof: Recall that $\Theta_{d B}$ is decreasing and $\Theta_{x B}$ is increasing in $\tau$. This implies that $\delta_{d B} / \delta_{x B}$ is increasing in $\tau$. (22) implies that $\tau^{\frac{-\beta}{1-\beta}} \Theta_{x B} / \Theta_{d B}$ is increasing in $\tau$. Next, $\Theta_{x B} / \Theta_{d B}$ and $\delta_{d B} / \delta_{x B}$ are decreasing in $b_{A} / b_{B}$. These considerations, together with (30), imply that $\bar{b}(\tau)$ is unique and increasing in $\tau$ whenever it is finite. ${ }^{50}$ Finally, $Q_{A} / Q_{B}$ is decreasing in $b_{A} / b_{B}$. Therefore, from (23), $M_{A}>0$ whenever $b_{A} / b_{B}<\bar{b}(\tau)$ and $M_{A}=0$ whenever $b_{A} / b_{B} \geq \bar{b}(\tau)$.

Evidently, Lemma 6 implies that there is an upper bound on how different the relative labor market frictions can be in the two countries for complete specialization not to occur in equilibrium. As we show in the numerical examples of Section 5.2, a wide range of $b_{A} / b_{B}>1$ is consistent with incomplete specialization equilibrium. See the working paper version, Helpman and Itskhoki (2008), for the analysis of equilibria with complete specialization.

\footnotetext{
${ }^{49}$ In the special case of a Pareto distribution, (30) is a ray through the origin.

${ }^{50}$ Note that $\bar{b}(\tau)>1$ by construction, since $\Theta_{x B}=\Theta_{d B} \tau^{\beta /(1-\beta)} f_{x} / f_{d}$ when $b_{A}=b_{B}$.
} 


\section{Proof of Lemmas 1-5 and Proposition 3}

Proof of Lemma 1 follows immediately from (22). First note that in equilibria with $\Theta_{d j}<\Theta_{x j}$, we have $\Delta=\frac{1-\beta}{\beta}\left(\delta_{d A} \delta_{d B}-\delta_{x A} \delta_{d B}\right)>0$. Indeed, $\Theta_{d j}<\Theta_{x j}$ implies

$$
\frac{\delta_{d j}}{\delta_{x j}}>\frac{f_{d}}{f_{x}} \frac{\Theta_{x j}}{\Theta_{d j}} .
$$

Using these inequalities for $j=A, B$ together with (21) implies $\delta_{d A} \delta_{d B} /\left(\delta_{x A} \delta_{x B}\right)>\tau^{2 \beta /(1-\beta)}>1$, in which case $\Delta>0 .{ }^{51}$ Then an increase in $b_{A} / b_{B}$ reduces $\Theta_{d A}$ and $\Theta_{x B}$ and increases $\Theta_{d B}$ and $\Theta_{x A}$ (see (22)). Therefore, $b_{A}>b_{B}$ implies $\Theta_{d A}<\Theta_{d B}$ and $\Theta_{x A}>\Theta_{x B}$ since in a symmetric equilibrium these relationships hold with equality.

Proof of Lemma 2 also follows immediately from (22) and the fact that $\delta_{d j}>\delta_{x j}$, which we prove below (Lemma 4).

Proof of Lemma 3 follows from (19) and Lemma 1. Note that (19) implies:

$$
\left(\frac{Q_{A}}{Q_{B}}\right)^{\frac{\beta-\zeta}{1-\beta}}=\frac{\Theta_{d A}}{\Theta_{d B}}\left(\frac{b_{B}}{b_{A}}\right)^{\frac{\beta}{1-\beta}} .
$$

When $b_{A}>b_{B}$, Lemma 1 implies $\Theta_{d A}<\Theta_{d B}$ and hence we have $Q_{A}<Q_{B}$.

Proof of Lemma 4 follows from (23), the incomplete specialization requirement $M_{j}>0$ and Lemmas 1 and 3. Specifically, when $b_{A}>b_{B}, M_{A}>0$ together with (23) imply

$$
\frac{\delta_{d B}}{\delta_{x B}}>\left(\frac{Q_{B}}{Q_{A}}\right)^{\zeta}>1,
$$

where the last inequality follows from Lemma 3. Lemma 1 implies that $\delta_{d A}>\delta_{d B}$ and $\delta_{x A}<\delta_{x B}$ since $\delta_{z j}$ is a decreasing function of $\Theta_{z j}(z=d, x$ and $j=A, B)$. Therefore, $\delta_{d A} / \delta_{x A}>\delta_{d A} / \delta_{x A}>1$.

Proof of Lemma 5 follows from (23) and Lemmas 3 and 4. Specifically, (23) implies

$$
M_{A}-M_{B}=\frac{(1-\beta) \phi_{2}}{\beta \Delta}\left[\left(\delta_{d B}+\delta_{x A}\right) Q_{A}^{\zeta}-\left(\delta_{d A}+\delta_{x B}\right) Q_{B}^{\zeta}\right]
$$

When $b_{A}>b_{B}$, Lemma 3 implies $Q_{A}<Q_{B}$ and Lemma 4 implies $\delta_{d A}>\delta_{d B}>\delta_{x B}>\delta_{x A}$. Therefore, in this case $M_{A}<M_{B}$.

Proof of Proposition 3 follows from Lemmas 1, 4 and 5 and the definition of intra-industry trade. When $b_{A}>b_{B}$, Lemma 1 states that $\Theta_{x A}>\Theta_{x B}$ and $\Theta_{d A}<\Theta_{d B}$ which implies that a larger fraction of firms export in country $B:\left[1-G\left(\Theta_{x j}\right)\right] /\left[1-G\left(\Theta_{d j}\right)\right]$ is greater in $B$.

In the text we show that exports of differentiated products is equal to $X_{j}=M_{j} \delta_{x j} / \phi_{2}$. When $b_{A}>b_{B}$, Lemma 4 states that $\delta_{x B}>\delta_{x A}$ and Lemma 5 states that $M_{B}>M_{A}$, which implies $X_{B}>X_{A}$; that is country $B$ exports differentiated goods on net. Balanced trade implies that is has to import the homogenous good.

\footnotetext{
${ }^{51}$ This also implies $\delta_{d j}>\delta_{x j}$ in at least one country and in both countries in the vicinity of a symmetric equilibrium.
} 
In the text the share of intra-industry trade is shown to equal $X_{A} / X_{B}=\delta_{x A} M_{A} /\left(\delta_{x B} M_{B}\right)$. Using (23), we have:

$$
\frac{X_{A}}{X_{B}}=\frac{\frac{\delta_{d B}}{\delta_{x B}}-\left(\frac{Q_{B}}{Q_{A}}\right)^{\zeta}}{\frac{\delta_{d A}}{\delta_{x A}}\left(\frac{Q_{B}}{Q_{A}}\right)^{\zeta}-1}
$$

From (22) and (26) and using Lemma 4 , an increase in $b_{A} / b_{B}$ leads to a decrease in $\delta_{d B} / \delta_{x B}$ and to increases in $\delta_{d A} / \delta_{x A}$ and $Q_{B} / Q_{A}$. Therefore, an increase in $b_{A} / b_{B}$ reduces $X_{A} / X_{B}$.

In Appendix E, we prove additionally that under Pareto-distributed productivity the total volume of trade increases in the proportional gap between relative labor market frictions, $b_{A} / b_{B}$.

\section{Derivation of results on productivity for Section 4.3}

We first show that $\varphi_{z j}=\varphi\left(\Theta_{z j}\right)$ is monotonically increasing in $\Theta_{z j}$. The log-derivative of $\varphi\left(\Theta_{z j}\right)$ is

$$
\hat{\varphi}_{z j}=\Theta_{z j} G^{\prime}\left(\Theta_{z j}\right)\left[\frac{\Theta_{z j}}{\int_{\Theta_{z j}}^{\infty} \Theta d G(\Theta)}-\frac{\Theta_{z j}^{1 / \beta}}{\int_{\Theta_{z j}}^{\infty} \Theta^{1 / \beta} d G(\Theta)}\right] \hat{\Theta}_{z j} \quad \text { for } z=d, x .
$$

The term in the square brackets is positive since

$$
\frac{\Theta_{z j}^{1 / \beta}}{\int_{\Theta_{z j}}^{\infty} \Theta^{1 / \beta} \frac{d G(\Theta)}{1-G\left(\Theta_{z j}\right)}}<\left(\frac{\Theta_{z j}}{\int_{\Theta_{z j}}^{\infty} \Theta_{\frac{d G(\Theta)}{1-G\left(\Theta_{z j}\right)}}}\right)^{1 / \beta}<\frac{\Theta_{z j}}{\int_{\Theta_{z j}}^{\infty} \Theta^{1 / \beta} \frac{d G(\Theta)}{1-G\left(\Theta_{z j}\right)}}
$$

where the first inequality follows from Jensen's inequality and the second inequality comes from the fact that $\beta<1$ and $\Theta_{z j}<\int_{\Theta_{z j}}^{\infty} \Theta \frac{d G(\Theta)}{1-G\left(\Theta_{z j}\right)}$.

Next we provide the general expression for a log-change in aggregate productivity:

$$
\widehat{T F P}_{j}=\left\{1+\frac{\kappa_{d j}}{\varphi_{x j}-\varphi_{d j}}\left[\frac{\kappa_{x j}}{\kappa_{d j}}\left(\Theta_{x j}^{\frac{1-\beta}{\beta}}-T F P_{j}\right)+\left(T F P_{j}-\Theta_{d j}^{\frac{1-\beta}{\beta}}\right)\right]\right\} \frac{\delta_{d j}\left(\varphi_{x j}-\varphi_{d j}\right)}{\delta_{d j} \varphi_{d j}+\delta_{x j} \varphi_{x j}} \hat{\Theta}_{d j}
$$

where

$$
\kappa_{z j} \equiv \kappa\left(\Theta_{z j}\right)=\frac{f_{z} \Theta_{z j} G^{\prime}\left(\Theta_{z j}\right)}{\delta_{z j}}=\frac{\Theta_{z j} G^{\prime}\left(\Theta_{z j}\right)}{\frac{1}{\Theta_{z j}} \int_{\Theta_{z j}}^{\infty} \Theta d G(\Theta)} .
$$

A series of sufficient conditions can be suggested for the terms in curly brackets to be positive. Since $T F P_{j} \geqslant \Theta_{d j}^{(1-\beta) / \beta}$ is always true, it is sufficient to require that

$$
T F P_{j} \leqslant \Theta_{x j}^{(1-\beta) / \beta}
$$

which holds for large enough $\Theta_{x j}$, i.e., when the economy is relatively closed. However, this inequality fails to hold when $\Theta_{x j}$ approaches $\Theta_{d j}$. If this condition fails, it is sufficient to have

$$
\left[T F P_{j}-\Theta_{d j}^{(1-\beta) / \beta}\right] /\left[T F P_{j}-\Theta_{x j}^{(1-\beta) / \beta}\right] \geqslant \kappa_{x j} / \kappa_{d j}
$$

which is, in particular, satisfied when $\kappa_{d j} \geqslant \kappa_{x j}$. This latter condition is always satisfied if $\kappa(\cdot)$ is a non- 
increasing function and is equivalent to

$$
-\frac{\Theta G^{\prime \prime}(\Theta)}{G^{\prime}(\Theta)} \geq 2+\frac{\Theta G^{\prime}(\Theta)}{\frac{1}{\Theta} \int_{\Theta}^{\infty} \xi d G(\xi)}
$$

that is, $G^{\prime \prime}(\cdot)$ has to be negative and large enough in absolute value. This condition is satisfied for the Pareto distribution since in this case $\kappa(\cdot)$ is constant and $\kappa_{d j} \equiv \kappa_{x j}$. However, it is not satisfied, for example, for the exponential distribution.

Finally, the necessary and sufficient condition is

$$
\left(\kappa_{x j}-\kappa_{d j}\right) T F P_{j}-\left(\kappa_{x j} \Theta_{x j}^{(1-\beta) / \beta}-\kappa_{d j} \Theta_{d j}^{(1-\beta) / \beta}\right) \leqslant \varphi_{x j}-\varphi_{d j}
$$

which is satisfied when

$$
\frac{\left(\kappa_{x j}-\kappa_{d j}\right)\left(T F P_{j}-\Theta_{d j}^{(1-\beta) / \beta}\right)}{\varphi_{x j}-\varphi_{d j}}=\left(\kappa_{x j}-\kappa_{d j}\right)\left[\varpi_{x j}+\frac{\varphi_{d j}-\Theta_{d j}^{(1-\beta) / \beta}}{\varphi_{x j}-\varphi_{d j}}\right] \leqslant 1 .
$$

This condition also does not hold in general; however, it is certainly satisfied for large enough $\Theta_{x j}$.

Now we provide the derivation of equation (29) under the assumption of Pareto-distributed productivity draws. When $\Theta$ is distributed Pareto with the shape parameter $k>1 / \beta$, there is a straightforward way of computing the change in $T F P_{j}$. Taking the log derivative of (28), we have

$$
\widehat{T F P}_{j}=\left[\frac{\delta_{d j} \varphi_{d j} \hat{\delta}_{d j}+\delta_{x j} \varphi_{x j} \hat{\delta}_{x j}}{\delta_{d j} \varphi_{d j}+\delta_{x j} \varphi_{x j}}-\frac{\delta_{d j} \hat{\delta}_{d j}+\delta_{x j} \hat{\delta}_{x j}}{\delta_{d j}+\delta_{x j}}\right]+\frac{\delta_{d j} \varphi_{d j} \hat{\varphi}_{d j}+\delta_{x j} \varphi_{x j} \hat{\varphi}_{x j}}{\delta_{d j} \varphi_{d j}+\delta_{x j} \varphi_{x j}} .
$$

Under the Pareto assumption, the free-entry condition (20) can be written as $\delta_{d j}+\delta_{x j}=k f_{e}$, which implies $\delta_{d j} \hat{\delta}_{d j}+\delta_{x j} \hat{\delta}_{x j}=0$. We use this to simplify

$$
\widehat{T F P}_{j}=\frac{\delta_{d j} \varphi_{d j}\left(\hat{\delta}_{d j}+\hat{\varphi}_{d j}\right)+\delta_{x j} \varphi_{x j}\left(\hat{\delta}_{x j}+\hat{\varphi}_{x j}\right)}{\delta_{d j} \varphi_{d j}} .
$$

Next note that $\delta_{z j}=f_{z} \frac{k}{k-1}\left(\Theta_{\min } / \Theta_{z j}\right)^{k}$ so that $\hat{\delta}_{z j}=-k \hat{\Theta}_{z j}$ and $\varphi_{z j}=\frac{k-1}{k-1 / \beta} \Theta_{z j}^{(1-\beta) / \beta}$, implying $\hat{\varphi}_{z j}=$ $(1-\beta) / \beta \hat{\Theta}_{z j}$. Thus, the log-derivative of the free-entry condition can also be written as $\delta_{d j} \hat{\Theta}_{d j}+\delta_{x j} \hat{\Theta}_{x j}=0$. Therefore,

$$
\delta_{d j}\left(\hat{\delta}_{d j}+\hat{\varphi}_{d j}\right)=-\delta_{x j}\left(\hat{\delta}_{x j}+\hat{\varphi}_{x j}\right)=-[k-(1-\beta) / \beta] \delta_{d j} \hat{\Theta}_{d j} .
$$

Using this, we obtain our result (29) in the text.

Finally, we discuss an alternative measure of productivity which takes into account the sectoral composition of resource allocation:

$$
T F P_{j}^{\prime}=\frac{L-N_{j}}{L} \frac{H_{0 j}}{N_{0 j}}+\frac{N_{j}}{L} \frac{H_{j}}{N_{j}} T F P_{j},
$$

which is a weighted average of $x_{0 j}=H_{0 j} / N_{0 j}$ (the productivity in the homogenous sector) and $T F P_{j}^{\prime \prime} \equiv$ $x_{j} \cdot T F P_{j}$ (productivity in the differentiated-product sector). The weights are the respective fractions of the two sectors in the labor force. Note that both sectoral productivity measures take into account unemployment of labor. Further, note that ${\widehat{T F P_{j}^{\prime \prime}}}^{\prime \prime} \widehat{T F P}_{j}+\hat{x}_{j}$. If $T F P_{j}^{\prime \prime}>x_{0 j}$, an extensive margin increase in the size of the differentiated sector improves productivity. Reduction in trade costs or labor market frictions in the 
differentiated sector (decreases in $a_{j} / a_{0 j}$ ) shift resources towards the differentiated sector by increasing $N_{j}$. Moreover, decreases in labor market frictions improve sectoral labor market tightness and hence increase productivity. These are the additional effects captured by this alternative measure of aggregate productivity.

\section{E Solution under Pareto assumption for Section 5.2}

We characterize here the solution of the model under the assumption that productivity draws $\Theta$ are distributed Pareto with the shape parameter $k>2$. That is, $G(\Theta)=1-\left(\Theta_{\min } / \Theta\right)^{k}$ defined for $\Theta \geq \Theta_{\min }$. We use this characterization in Section 5.2 in order to solve numerically for the equilibrium response of unemployment to different shocks. In the end of this appendix we provide some analytical results under Pareto-distributed productivity referred to in the text.

Pareto-distributed productivity leads to the following useful functional relationship:

$$
\delta_{z j} \equiv \frac{f_{z}}{\Theta_{z j}} \int_{\Theta_{z j}}^{\infty} \Theta d G(\Theta)=f_{z} \frac{k}{k-1}\left(\frac{\Theta_{\min }}{\Theta_{z j}}\right)^{k}, \quad z=d, x
$$

so that $\hat{\delta}_{z j}=-k \hat{\Theta}_{d j}$. As a result, we can rewrite the free entry condition (20) as

$$
f_{d} \Theta_{d j}^{-k}+f_{x} \Theta_{x j}^{-k}=(k-1) f_{e} \Theta_{\min }^{-k} \quad \Leftrightarrow \quad \delta_{d j}+\delta_{x j}=k f_{e} .
$$

Manipulating cutoff conditions (19) and the free entry condition above, we can obtain two equations to solve for $\left\{\Theta_{d j}, \Theta_{x j}\right\}$. For concreteness, consider $j=A$ :

$$
\begin{gathered}
f_{d} \Theta_{d A}^{-k}+f_{x} \Theta_{x A}^{-k}=(k-1) f_{e} \Theta_{\min }^{-k}, \\
f_{x}\left[\tau^{\frac{\beta}{1-\beta}} \frac{f_{x}}{f_{d}} \psi^{-\frac{\beta}{1-\beta}}\right]^{-k} \Theta_{d A}^{-k}+f_{d}\left[\tau^{\frac{\beta}{1-\beta}} \frac{f_{x}}{f_{d}} \psi^{\frac{\beta}{1-\beta}}\right]^{k} \Theta_{x A}^{-k}=(k-1) f_{e} \Theta_{\min }^{-k},
\end{gathered}
$$

where $\psi \equiv b_{A} / b_{B}$ is the relative labor market rigidity of country $A$. This is a linear system in $\left\{\Theta_{d A}^{-k}, \Theta_{x A}^{-k}\right\}$ and there are similar conditions for country $B$, with $\psi^{-1}$ replacing $\psi$. The solution to this system is given by

$$
\begin{aligned}
& \Theta_{d A}^{-k}=\frac{f_{x}}{\Delta_{\Theta}}\left[\tau^{\frac{\beta k}{1-\beta}}\left(\frac{f_{x}}{f_{d}}\right)^{k-1} \psi^{\frac{\beta k}{1-\beta}}-1\right], \\
& \Theta_{x A}^{-k}=\frac{f_{d}}{\Delta_{\Theta}}\left[1-\tau^{\frac{-\beta k}{1-\beta}}\left(\frac{f_{x}}{f_{d}}\right)^{-(k-1)} \psi^{\frac{\beta k}{1-\beta}}\right],
\end{aligned}
$$

where

$$
\Delta_{\Theta}=\frac{f_{x}^{2} \Theta_{\min }^{k}}{(k-1) f_{e}} \tau^{\frac{-\beta k}{1-\beta}}\left(\frac{f_{x}}{f_{d}}\right)^{-k} \psi^{\frac{\beta k}{1-\beta}}\left[\tau^{\frac{2 \beta}{1-\beta}}\left(\tau^{\frac{\beta}{1-\beta}} \frac{f_{x}}{f_{d}}\right)^{2(k-1)}-1\right]>0 .
$$

Using this result we can derive a condition on primitive parameters for $\Theta_{d j}<\Theta_{x j}$ to hold in equilibrium:

$$
\frac{f_{d}}{f_{d}+f_{x}}\left(\tau^{\frac{\beta}{1-\beta}} \frac{f_{x}}{f_{d}}\right)^{k}+\frac{f_{x}}{f_{d}+f_{x}}\left(\tau^{\frac{\beta}{1-\beta}} \frac{f_{x}}{f_{d}}\right)^{-k}>\max \left\{\psi^{\frac{-\beta k}{1-\beta}}, \psi^{\frac{\beta k}{1-\beta}}\right\}
$$

which is satisfied for large $\tau$ and for $\psi \equiv b_{A} / b_{B}$ not very different from one. Next note that as $\tau \rightarrow \infty$, $\Theta_{x A} \rightarrow \infty$ and $\Theta_{d A} \rightarrow\left[\frac{f_{d}}{(k-1) f_{e}}\right]^{1 / k} \Theta_{\min } \equiv \Theta_{d}^{c}$. Therefore, the condition for $\Theta_{d}^{c}>\Theta_{\min }$ is $k<1+f_{d} / f_{e}$ 
which is equivalent to the condition in the text. One can also show that $\Theta_{d A}$ decreases in $\tau$ in the range $\tau \in\left(\tau^{*}, \infty\right)$ where

$$
\tau^{*}=\tau^{*}\left(\psi, f_{x} / f_{d}\right): \quad\left(\tau^{*}\right)^{\frac{\beta k}{1-\beta}}=\left(f_{d} / f_{x}\right)^{k-1}\left(\psi^{\frac{\beta k}{1-\beta}}+\sqrt{\psi^{\frac{2 \beta k}{1-\beta}}-1}\right) .
$$

The first cutoff condition in (19) allows to solve for $Q_{j}$ once $\Theta_{d j}$ is known; $Q_{j}$ is also decreasing in $\tau$ in the range $\left(\tau^{*}, \infty\right)$. It is straightforward to show that $Q_{j}$ decreases in $b_{A}$ and increases in $b_{B}$. Using the Pareto assumption and the equation for $M_{j}(23)$, we get

$$
M_{j}=\phi_{2} \frac{k-1}{k} \Theta_{\min }^{-k} \frac{f_{d} Q_{j}^{\zeta} \Theta_{d(-j)}^{-k}-f_{x} Q_{(-j)}^{\zeta} \Theta_{x(-j)}^{-k}}{f_{d}^{2} \Theta_{d A}^{-k} \Theta_{d B}^{-k}-f_{x}^{2} \Theta_{x A}^{-k} \Theta_{x B}^{-k}} .
$$

The condition for $M_{A}>0$ can then be written as

$$
\left(\frac{\Theta_{x B}}{\Theta_{d B}}\right)^{k}\left(\frac{Q_{A}}{Q_{B}}\right)^{\zeta}>1
$$

One can show that this inequality imposes a restriction on parameters $\left\{\tau, \psi, f_{x} / f_{d}\right\}$ such that $\tau>\tau^{*}\left(\psi, f_{x} / f_{d}\right)$, which implies that $Q_{j}$ is decreasing in $\tau$ whenever there is no complete specialization $\left(M_{j}>0\right.$ for both $\left.j\right)$. This is consistent with Lemma 2 in the text.

Finally, using the condition for $N_{j}(24)$ and the free entry condition under the Pareto assumption, we get:

$$
\omega_{0 j} N_{j}=\phi_{1}^{\frac{1-\beta}{\beta}} \phi_{2}^{-1} M_{j}\left[\delta_{d j}+\delta_{x j}\right]=\phi_{1}^{\frac{1-\beta}{\beta}} k f_{e} M_{j}
$$

That is, under the Pareto assumption, $N_{j}$ is always proportional to $M_{j}$. The remaining equilibrium condition is $H_{j}=x_{j} N_{j}$ and the expression for unemployment (18). Labor market tightness in the two sectors and the expected income $\omega_{0 j}$ are still determined by (12), (13) and (17). We use the equations above to solve for equilibrium comparative statics numerically. Additional analytical results can also be obtained under the Pareto assumption for $M_{j}, N_{j}$ and $u_{j}$ departing from (33).

Volume of Trade (remark for Section 4.3) Under the Pareto assumption we can get a simple prediction about the response of the trade volume to $\tau, b_{A}$ and $b_{B}$. Recall that the total volume of trade (when $b_{A}>b_{B}$ ) equals $2 X_{B}$ where we have

$$
X_{B}=\phi_{2}^{-1} M_{B} \delta_{x B}=\frac{\frac{\delta_{d A}}{\delta_{x A}} Q_{B}^{\zeta}-Q_{A}^{\zeta}}{\frac{\delta_{d A} \delta_{d B}}{\delta_{x A} \delta_{x B}}-1}=\frac{\frac{f_{d}}{f_{x}}\left(\frac{\Theta_{x A}}{\Theta_{d A}}\right)^{k} Q_{B}^{\zeta}-Q_{A}^{\zeta}}{\frac{f_{d}^{2}}{f_{x}^{2}}\left(\frac{\Theta_{x A} \Theta_{x B}}{\Theta_{d A} \Theta_{d B}}\right)^{k}-1}=\frac{\frac{f_{d}}{f_{x}}\left(\frac{\Theta_{x A}}{\Theta_{d A}}\right)^{k} Q_{B}^{\zeta}-Q_{A}^{\zeta}}{\tau^{\frac{2 \beta k}{1-\beta}}\left(\frac{f_{x}}{f_{d}}\right)^{2(k-1)}-1} .
$$

As $b_{A}$ increases or $b_{B}$ falls, the denominator remains unchanged while $\Theta_{x A} / \Theta_{d A}$ and $Q_{B}$ increase and $Q_{A}$ decreases. As a result the volume of trade unambiguously rises. Finally, one can also show that $X_{B}$ decreases in $\tau$. Substitute the expression for $\Theta_{x A} / \Theta_{d A}$ (derived from (19)) in the expression for $X_{B}$ to get

$$
X_{B}=Q_{A}^{\zeta} \frac{\tau^{\frac{\beta k}{1-\beta}}\left(\frac{f_{x}}{f_{d}}\right)^{k-1}\left(\frac{Q_{B}}{Q_{A}}\right)^{\zeta+k \frac{\beta-\zeta}{1-\beta}}-1}{\tau^{\frac{2 \beta k}{1-\beta}}\left(\frac{f_{x}}{f_{d}}\right)^{2(k-1)}-1} .
$$

Now note that $X_{B}$ decreases in $\tau$ since $Q_{A}$ and $Q_{B} / Q_{A}$ decrease in $\tau$ and $Q_{B}>Q_{A}$. 
Proof that $N_{A} / N_{B}$ decreases in $\tau$ when $b_{A}>b_{B}$ In the text we show that $N_{A}+N_{B}$ increases as $\tau$ falls. We show now that when $b_{A}>b_{B}, N_{A} / N_{B}$ decreases as $\tau$ falls, which implies that $N_{B}$ necessarily increases. Under the Pareto assumption $\delta_{d j}+\delta_{x j}=k f_{e}$. Therefore, (23) and (24) imply

$$
\frac{\omega_{0 A} N_{A}}{\omega_{0 B} N_{B}}=\frac{M_{A}}{M_{B}}=\frac{\delta_{d B} Q_{A}^{\zeta}-\delta_{x B} Q_{B}^{\zeta}}{\delta_{d A} Q_{B}^{\zeta}-\delta_{x A} Q_{A}^{\zeta}}=\frac{1-\frac{\delta_{x B}}{k f_{e}}\left[1+\left(\frac{Q_{B}}{Q_{A}}\right)^{\zeta}\right]}{\frac{\delta_{d A}}{k f_{e}}\left[1+\left(\frac{Q_{B}}{Q_{A}}\right)^{\zeta}\right]-1}<1,
$$

where the last inequality comes from Lemma 5 under the assumption that $b_{A}>b_{B}$. Recall that $\omega_{0 A} / \omega_{0 B}$ depends only on $a_{0 A} / a_{0 B}$ and does not depend on $\tau$. From Proposition $1, Q_{B} / Q_{A}$ increases as $\tau$ falls. Taking this and the fact that $N_{A}<N_{B}$ into account, it is sufficient to show that $d \delta_{x B}-d \delta_{d A}=\delta_{x B} \hat{\delta}_{x B}-$ $\delta_{d A} \hat{\delta}_{d A}>0$ in response to a fall in $\tau$, to establish that $N_{A} / N_{B}$ declines in this case. Under Pareto-distributed productivity,

$$
\frac{\delta_{x B} \hat{\delta}_{x B}-\delta_{d A} \hat{\delta}_{d A}}{-\hat{\tau}}=\frac{k\left(\delta_{d A} \hat{\Theta}_{d A}-\delta_{x B} \hat{\Theta}_{x B}\right)}{-\hat{\tau}}=k \frac{\left(\delta_{d B} \delta_{x B}-\delta_{d A} \delta_{x A}\right)\left(\delta_{d A}-\delta_{x A}\right)}{\Delta}>0,
$$

where the second equality comes from (22) and the inequality is obtained by Lemma 4 and the fact that under the Pareto assumption $\delta_{d A}+\delta_{x A}=\delta_{d B}+\delta_{x B}=k f_{e}$. This proves that $N_{B}$ increases as $\tau$ falls when $b_{A}>b_{B}$. Since changes in $\tau$ do not affect labor market tightness, $x_{0 B}$ and $x_{B}$, the only effect on the unemployment rate $u_{B}$ is through $N_{B}$, and hence the unemployment rate in the flexible country increases in response to trade liberalization. 


\section{References}

[1] Agell, Jonas and Per Lundborg (1995), "Fair Wages in the Open Economy," Economica 62, pp. 335-351.

[2] Alessandria, George and Alain Delacroix (2008), "Trade and the (Dis)Incentive to Reform Labor Markets: The Case of Reform in the European Union," Journal of International Economics 75, pp. 151-166.

[3] Amiti, Mary and Christopher Pissarides (2005), "Trade and Industrial Location with Heterogeneous Labour," Journal of International Economics 67, pp. 392-412.

[4] Bernard, Andrew B. and J. Bradford Jensen (1995), "Exporters, Jobs, and Wages in US Manufacturing: 1976-87," Brookings Papers on Economic Activity: Microeconomics, pp. 67112.

[5] Blanchard, Olivier and Jordi Gali (2008), "Labor Markets and Monetary Policy: A NewKeynesian Model with Unemployment," NBER Working Paper No. 13897.

[6] Blanchard, Olivier and Justin Wolfers (2000), "The Role of Shocks and Institutions in the Rise of European Unemployment: The Aggregate Evidence," Economic Journal 110, pp. C1-C33.

[7] Botero, Juan C., Simeon Djankov, Rafael La Porta, Florencio Lopez-de-Silanes and Andrei Shleifer (2004), "The Regulation of Labor," Quarterly Journal of Economics 119, pp. 13391382 .

[8] Brecher, Richard (1974), "Minimum Wage Rates and the Pure Theory of International Trade," Quarterly Journal of Economics 88, pp. 98-116.

[9] Brecher, Richard (1992), "An Efficiency-Wage Model with Explicit Monitoring: Unemployment and Welfare in an Open Economy," Journal of International Economics 32, pp. 179-191.

[10] Brügemann, Björn (2003), "Trade Integration and the Political Support for Labor Market Rigidity," mimeo, Yale University.

[11] Chor, Davin (2006), "Unpacking Sources of Comparative Advantage: A Quantitative Approach," mimeo, Harvard University.

[12] Copeland, Brian (1989), "Efficiency Wages in a Ricardian Model of International Trade," Journal of International Economics 27, pp. 221-244.

[13] Costinot, Arnaud (2006), "On the Origins of Comparative Advantage," mimeo, UCSD.

[14] Cuñat, Alejandro and Marc Melitz (2007), "Volatility, Labor Market Flexibility, and the Pattern of Comparative Advantage," NBER Working Paper No. 13062. 
[15] Davidson, Carl, Lawrence Martin and Steven Matusz (1988), "The Structure of Simple General Equilibrium Models with Frictional Unemployment," Journal of Political Economy 96, pp. 1267-1293.

[16] Davidson, Carl, Lawrence Martin and Steven Matusz (1999), "Trade and Search Generated Unemployment," Journal of International Economics 48, pp. 271-299.

[17] Davidson, Carl and Steven Matusz (2006a), "Long-run Lunacy, Short-run Sanity: a Simple Model of Trade with Labor Market Turnover," Review of International Economics 14, pp. 261-276.

[18] Davidson, Carl and Steven Matusz (2006b), "Trade Liberalization and Compensation," International Economic Review 47, pp. 723-747.

[19] Davis, Donald (1998), "Does European Unemployment Prop Up American Wages? National Labor Markets and Global Trade," American Economic Review 88, pp. 478-494.

[20] Davis, Donald and James Harrigan (2007), "Good Jobs, Bad Jobs, and Trade Liberalization," mimeo, Columbia University.

[21] Demidova, Svetlana (2008), "Productivity Improvements and Falling Trade Costs: Boon or Bane?" International Economic Review 49, 1437-1462.

[22] Egger, Harmut and Udo Kreickemeier (2009), "Firm Heterogeneity and the Labour Market Effects of Trade Liberalization," International Economic Review 50, 187-216.

[23] Fariñas, José C. and Ana Martín-Marcos (2007), "Exporting and Economic Performance: Firm-Level Evidence of Spanish Manufacturing," The World Economy 30, 618-646.

[24] Felbermayr, Gabriel, Julien Prat and Hans-Jörg Schmerer (2008), "Globalization and Labor Market Outcomes: Wage Bargaining, Search Frictions, and Firm Heterogeneity," IZA Discussion Papers 3363.

[25] Harris J. and M. Todaro (1970), "Migration, Unemployment and Development: A Two-Sector Analysis," American Economic Review 60, 126-142.

[26] Helpman, Elhanan and Paul R. Krugman (1985), Market Structure and Foreign Trade (Cambridge, MA: MIT Press).

[27] Helpman, Elhanan and Oleg Itskhoki (2008), "Labor Market Rigidities, Trade and Unemployment," Harvard University, http://www.economics.harvard.edu/faculty/helpman/files/LaborMarketRigidities.pdf.

[28] Helpman, Elhanan and Oleg Itskhoki (2009), "Labor Market Rigidities, Trade and Unemployment: A Dynamic Model," Harvard University, http://www.economics.harvard.edu/faculty/helpman/files/LaborMarketRigidities_Dynamic.pdf. 
[29] Helpman, Elhanan, Oleg Itskhoki and Stephen Redding (2009), "Inequality and Unemployment in a Global Economy," in preparation.

[30] Hoon, Hian Teck (2001), "Adjustment of Wages and Equilibrium Unemployment in a Ricardian Global Economy," Journal of International Economics 54, pp. 193-209.

[31] Hosios, Arthur J. (1990), "Factor Market Search and the Structure of Simple General Equilibrium Models," Journal of Political Economy 98, pp. 325-355.

[32] Jones, Ronald W. (1965), "The Structure of Simple General Equilibrium Models," Journal of Political Economy 73, pp. 557-572.

[33] Kreickemeier, Udo and Douglas Nelson (2006), "Fair Wages, Unemployment and Technological Change in a Global Economy," Journal of International Economics 70, pp. 451-469.

[34] Levchenko, Andrei A. (2007), "Institutional Quality and International Trade," forthcoming in the Review of Economic Studies 74, pp. 791-819.

[35] Matusz, Steven J. (1986), "Implicit Contracts, Unemployment and International Trade," Economic Journal 96, pp. 71-84.

[36] Melitz, Marc J. (2003), "The Impact of Trade on Intra-Industry Reallocations and Aggregate Industry Productivity," Econometrica 71, pp. 1695-1725.

[37] Mitra, Devashish and Priya Ranjan (2007), "Offshoring and Unemployment," mimeo, Syracuse University.

[38] Moore, Mark P. and Priya Ranjan (2005), "Globalisation vs Skill-Biased Technological Change: Implications for Unemployment and Wage Inequality," Economic Journal 115, pp. 391-422.

[39] Nickell, Steven (1997), "Unemployment and Labor Market Rigidities: Europe Versus NorthAmerica," Journal of Economic Perspectives 11, pp. 55-74.

[40] Nickell, Steven, Luca Nunziata, Wolfgang Ochel and Glenda Quintini (2002), "The Beveridge Curve, Unemployment and Wages in the OECD from the 1960s to the 1990s," Center for Economic Performance, the LSE.

[41] Nunn, Nathan (2007), "Relationship-Specificity, Incomplete Contracts, and the Pattern of Trade," Quarterly Journal of Economics CXXII, pp. 569-600.

[42] Pissarides, Christopher A. (2000), Equilibrium Unemployment Theory (Cambridge, MA: The MIT Press, second edition).

[43] Stole, Lars A. and Jeffrey Zwiebel (1996a), "Organizational Design and Technology Choice under Intrafirm Bargaining," American Economic Review 86, pp. 195-222. 
[44] Stole, Lars A. and Jeffrey Zwiebel (1996b), "Intra-Firm Bargaining under Non-Binding Contracts," Review of Economic Studies 63, pp. 375-410. 